\title{
Support from grandparents and mothers' depression around the time of separation
}

\author{
Niina Metsä-Simola I niina.metsa-simola@helsinki.fi \\ Anna Baranowska-Rataj \\ Hanna Remes \\ Mine Kühn I kuehn@demogr.mpg.de \\ Pekka Martikainen
}

\footnotetext{
This working paper has been approved for release by: Natalie Nitsche (nitsche@demogr.mpg.de), Deputy Head of the Laboratory of Fertility and Well-Being.

(C) Copyright is held by the authors.
} 


\title{
SUPPORT FROM GRANDPARENTS AND MOTHERS' DEPRESSION AROUND THE
}

\section{TIME OF SEPARATION}

Metsä-Simola, Niina ${ }^{1}$, Baranowska-Rataj, Anna ${ }^{2}$, Remes, Hanna ${ }^{1}$, Kühn, Mine ${ }^{3}$ \& Martikainen, Pekka $^{1,3,4}$

${ }^{1}$ Population Research Unit, University of Helsinki, Finland

${ }^{2}$ Department of Sociology and Center for Demographic and Ageing Research (CEDAR), Umeå University, Umeå, Sweden

${ }^{3}$ Max Planck Institute for Demographic Research, Rostock, Germany

${ }^{4}$ Department of Public Health Sciences, Stockholm University, Stockholm, Sweden

\begin{abstract}
Objective. This study examined mothers' depression trajectories around the time of separation by potential availability of support from their youngest child's grandparents.

Background. Separation and single motherhood are both associated with an increased risk of depression. Grandparents are often the most important source of support to families with children, and their support may moderate separating mothers' depression trajectories.

Method. Using longitudinal Finnish register data on 118,006 separating mothers whose youngest child was age 12 or less, we examined the mothers' depression trajectories, based on antidepressant use 4 years before and 4 years after separation. The trajectories were examined by grandparental characteristics - age, employment, health, geographical distance to the mother, and union stability - using logistic panel regression.

Results. Grandparent's availability for providing support, as proxied by younger age, employment, and lack of severe health problems all predicted a lower probability of maternal depression both before and after separation. The level of depression was also lower if grandparents lived close to the mother, and if the maternal grandparents' union was intact. Overall, the maternal grandmothers appeared to matter the most.

Conclusion. The availability of support from grandparents may partially compensate for the resource losses related to separation, and it is associated with lower maternal depression both before and after separation.
\end{abstract}

Keywords. Separation, depression, mothers, grandparents, social support 


\section{INTRODUCTION}

Separation is associated with adverse changes in mental health, which already start to emerge during the pre-separation period of conflict and uncertainty, and mainly resolve following separation (Amato, 2010; Raley \& Sweeney, 2020). However, the magnitude and persistence of these changes is suggested to depend on the social context, with the negative effects of separation being most pronounced among parents of young children (Kamp Dush, 2013; Raley \& Sweeney, 2020). Separation is also the main pathway into single motherhood (Bernardi \& Larenza, 2018), and single motherhood is known to be distressing and associated with mental health problems (Cooper et al., 2008). Most scholars attribute the mental health disadvantage of single mothers to the chronic economic strains many of them are exposed to, as well as social stressors associated with single-parenting responsibilities (Dziak et al., 2010). Among single mothers, mobilizing support within networks of family members and relatives is one of their key coping strategies (Radey \& McWey, 2019; Taylor \& Conger, 2017). Grandparents are often the most important source of this support, and there is evidence that grandparents provide more support to their adult children who are single parents than to their partnered children (Cooney, 2020; Dunifon et al., 2018), and that adult children also receive more help from their own parents when going through separation (Min et al., 2021).

After separation, contacts between grandchildren and grandparents are shown to improve the psychological well-being of both the children and the grandparents (Drew \& Silverstein, 2007; Henderson et al., 2009), which may benefit the well-being of the parents as well. However, the association between grandparental support and separating mothers' depression has only been investigated among single mothers, and the evidence provided by previous research on grandparental involvement and support and single mothers' depression or other measures of well- 
being is mixed. This may partly be because prior research has largely focused on either multigenerational co-residence or on a particular sub-group such as teen mothers, excluding the majority of all single mothers (Greenfield, 2011; Kalil et al., 1998; Piontak, 2016).

Taking advantage of longitudinal Finnish register data containing multiple generations, this study examines the moderating role of potential support from grandparents for separating mothers' depression trajectories. We include all grandparents, both from the mother's own side and the expartner's side, and examine important modifying characteristics that may affect the availability of support from grandparents; that is, their age, employment status, health conditions, geographical distance to the mother, and union stability (Aassve et al., 2012; Hank \& Buber, 2008).

Our study makes three key contributions to the previous literature. First, by examining the onset and persistence of depressive symptoms around the time of separation among mothers of young children, we further the understanding of how critical life-course events affect mental health within a vulnerable subpopulation such as separating mothers. Second, we provide new evidence on the importance of the social context in which critical life-course events occur by examining the moderating role of the potential availability of support from grandparents. Unlike many previous studies on grandparental support, we investigate both maternal and paternal grandparents. This allows us to assess the role of gender and lineage in how the potential availability of grandparental support may protect separating mothers from depression. The examination of demographic characteristics, health and geographic proximity of all grandparents provides a better understanding of how broader societal changes such as postponing childbearing and increasing spatial mobility may affect the availability of support within family networks in the future. Third, the association between grandparental support and separating mothers' depression has been investigated only among single mothers, and mostly among specific sub-groups such as teen 
mothers in Anglo-Saxon countries, making results difficult to generalize. In the pro-egalitarian Nordic countries, the welfare state provides a high level of universal services for families with children, including affordable early childhood education and care. Intergenerational co-residence is uncommon and daily childcare provided by grandparents is rare - yet the majority of grandparents provide at least occasional childcare (Aassve et al., 2012; Hank \& Buber, 2008). Given that in many countries the government has the ambition to improve the availability of formal childcare in order to raise parental employment levels and increase gender equality, it is central to understanding whether grandparental support still matters for mothers' mental health in institutional contexts such as Finland, where such policies are already in place.

\section{BACKGROUND}

\section{The Conservation of Resources (COR) Theory}

Depression among separating mothers, and the way it may be moderated by the potential availability of support from others, can be understood from the perspective of the conservation of resources (COR) theory (Hobfoll 2001). Adverse life-course events, such as separation, result in stress and strain not only due to the event itself, but also from the resource losses associated with the event (Hobfoll, 2001). These resources may be broadly defined as material and also nonmaterial entities that people value, such as time spent with family or emotional support (Hobfoll, 2002). COR emphasizes human motivation to protect against resource loss, and to acquire new resources. In the context of our study, separating mothers can be expected to engage in behaviors that help prevent substantial resource losses, for instance by maintaining and developing relationships with a broad network of family members, including grandparents from both the maternal and paternal side. Given that separation from a partner is often related to family-level conflicts that may spill over into relationships with multiple relatives, single mothers are 
particularly vulnerable to losing social resources. Thus, the question of whether and to what extent potential support from grandparents can play a protective role against depression is particularly salient for separating mothers. In line with the COR theory, single mothers' poor mental health seems to result mainly from the losses of material and social resources, but these adverse effects of resource loss, or the threat of resource loss, may be balanced by received or expected resource gains (Hobfoll, 2001). Accordingly, support from relatives and other social networks is one of the key coping strategies for single mothers (Radey \& McWey, 2019; Taylor \& Conger, 2017).

COR theory also posits that it is psychologically more harmful for individuals to lose resources than it is helpful for them to gain otherwise similar resources. Hence, we can expect potential support from grandparents after separation to only partially compensate for the resource losses that tend to follow separation. In addition, according to COR, individuals with more resources are better positioned for resource gains, whereas individuals with fewer resources, such as single mothers, are more likely to experience resource losses. Moreover, grandparental involvement in raising their grandchildren may also be a source of conflict and stress, and at times grandparents may be in need of support themselves, placing additional demands on the middle generation, often referred to as the "sandwich generation" (Greenfield, 2011). Having grandparents in poor health may even lead to upward care; that is, the parents need to care for their own parents instead of the grandparents providing care downwards (Margolis \& Wright, 2017). Thus, instead of resource gains, the grandparents may also be a further source of potential resource losses, exacerbating stress among separating parents. It is also common for parent-grandparent relationships to be characterized by ambivalence: positive feelings occurring alongside negative emotions, with family transitions altering their balance (Zartler et al., 2020).

Availability of Support from Grandparents 
Children's grandparents are an important source of support to parents, and they often represent the main source of informal childcare (Rutigliano, 2020). Although grandparental support may have the potential to buffer mothers from the negative effects of separation and single motherhood, several factors affect the availability of their support. On average, increasing grandparental age is negatively associated with grandparenting (Aassve et al., 2012). In Europe, grandparents in their fifties and sixties were most likely to provide childcare and other time-consuming help (AttiasDonfut et al., 2005). Grandparental age is closely intertwined with both employment and health. Although less likely to suffer from health problems, younger grandparents are often still employed and thus less available for childcare (Rutigliano, 2020). However, a survey in ten European countries showed that although working grandparents were less likely to provide regular childcare, their employment status was unrelated to their probability to provide occasional care (Aassve et al., 2012; Hank \& Buber, 2008). Previous studies largely agree that poor health decreases grandparental support (Aassve et al., 2012; Thomese \& Liefbroer, 2013), and even if unhealthy grandparents offer their support, the parents may not consider their care reliable (Aassve et al., 2012). Across European countries, limitations with activities of daily living predicted a lower probability to provide childcare to grandchildren (Hank \& Buber, 2008). Even if the grandparents are in good health and willing to provide support, geographical distance may limit their availability to provide childcare. In a survey conducted in ten European countries, the frequency of contact and likelihood of childcare decreased with increasing geographical distance between the parent and the grandparent generations, particularly for regular childcare (Hank, 2007; Hank \& Buber, 2008).

The Importance of Gender and Lineage 
Previous studies have consistently shown that maternal grandparents are more likely to provide support and to be involved in the lives of grandchildren, and that grandmothers are more active than grandfathers (Attias-Donfut et al., 2005; Hank \& Buber, 2008). In Western societies, women are usually more involved in maintaining social ties and fostering family solidarity than men, which makes intergenerational support more likely to follow the matrilineal pattern (Albertini \& Tosi, 2018; Bucx et al., 2012). It has also been suggested that maternal grandmothers have the greatest interest to care for grandchildren, because they can be certain to share lineage with them (Danielsbacka et al., 2011). Whereas married grandfathers had overall less contact with their adult children than grandmothers, after divorce these gender differences were further increased (Kalmijn, 2007). The grandmother's partnership status was either not at all or only weakly associated with her probability to provide support to adult children and grandchildren, but nonpartnered grandfathers were less likely to be involved than grandfathers living with a partner (Danielsbacka \& Tanskanen, 2018; Hank \& Buber, 2008).

Grandparental involvement is largely already established before the parents separate, suggesting that grandparents who were already strongly involved before the separation continue to do so, whereas disengaged grandparents may become even more disengaged (Douglas \& Ferguson, 2003). Furthermore, parents usually facilitate contact between grandparents and grandchildren, and after parental separation children's residential arrangements support the preservation of grandparental relationships in one lineage and help the custodial parent to control access to the other lineage (Albertini \& Tosi, 2018). Accordingly, children of separated parents have more contact with grandparents from the side of the parent they are living with (Jappens \& Bavel, 2016). Because grandparents provide more support to their adult children that are single parents, children living with a single mother may even have a higher level of contact with maternal grandparents 
than children living with both parents (Jappens \& Bavel, 2016; Westphal et al., 2015). The fact that most children reside with their mothers after separation is thus expected to accentuate the matrilineal pattern in intergenerational contacts following separation, and to lower the probability of support from the paternal grandparents (Albertini \& Tosi, 2018; Harknett \& Knab, 2007).

\section{The Present Study}

In this study, we examine whether factors that are known to affect the availability of support from grandparents are related to separating mothers' depression. Because grandparents that are younger, non-employed, in good health, living close, and in stable unions are more likely to provide support to their adult children and grandchildren, we may expect these grandparental characteristics to be associated with lower levels of maternal depression both at the time of separation and during single motherhood that follows separation. To investigate this hypothesis, we examine trajectories of depression among separating mothers. Because the need of grandparental support is often larger when children are young, for example with respect to childcare needs, our analyses focus on mothers of children age 12 or less (Hank \& Buber, 2008; Thomese \& Liefbroer, 2013). We follow the mothers for depression four years before and four years after separation, measuring depression with antidepressant purchases. We examine whether and how the separating mothers' depression trajectories depend on their youngest child's maternal and paternal grandparents' age, employment, health, geographical distance to the mother, and union stability - all known predictors of availability of grandparental childcare and support. We also adjust the analyses for several time-varying socio-demographic characteristics of the mothers, to account for differences in need of grandparental support.

\section{DATA AND METHODS}

\section{Sample}


We used Finnish register-based total population data on all Finnish-born mothers of children age 12 or less that separated from their biological child's father during 2000-2012 and continued to live with their child after the separation. The data contained information on all children, their biological parents, and both maternal and paternal grandparents, based on personal identification codes. We included only mothers that were born in Finland (85.6\%), because for foreign-born mothers the information on maternal grandparents was mainly missing. No linkages could be made to biological relatives deceased before 1968, the year when all permanent residents of Finland had received their personal identification codes. We included in our sample all separating mothers that could be linked to at least one maternal or paternal grandparent of their youngest child (99.6\%). For all the sample members, Statistics Finland provided annual socio-demographic and family information, including exact dates of separation from marital and non-marital cohabiting unions. These data were linked to information on medication purchases in the national prescription register maintained by the Social Insurance Institution, and information on inpatient and specialized outpatient hospital care in the Care Register maintained by the Finnish Institute for Health and Welfare. The registers have good quality and practically complete national coverage (Sund et al., 2014) and enabled the assessment of depression with minimal sample selection bias or loss to follow-up, which may be critical problems in survey-based studies. The data linkage was done by Statistics Finland (the Ethics Committee of Statistics Finland's permission TK-53-1121-18). All data were available from 1995 to 2017.

\section{Variables}

Family dissolution may result from any family member moving out of the household, or from death. We focused on dissolutions that result from the father moving out, and where the mother and child lived together in the year following dissolution. In case of multi-partner fertility, we 
followed separation from the youngest child's father. For marital dissolutions, the date of separation was usually before the date of formal divorce, because of a mandatory consideration period of at least six months. However, if the formal divorce occurred first, we recorded it as the date of separation.

Mothers' depression was measured with antidepressant (AD) purchases (ATC codes N06A) in the time period of four years preceding and following separation, drawing on previous research which shows that depressive symptoms already start to emerge during the pre-separation period of marital conflicts, and persist even a few years following separation (Amato, 2010; Raley \& Sweeney, 2020). In Finland, all ADs are prescribed by clinical doctors, and all permanent residents are entitled to reimbursement for medication expenses, usually provided directly at the pharmacy (Sihvo et al., 2008). The prescription register includes information on the date of purchase and the type of medication. Finland is a Nordic welfare state with universal healthcare, and general practitioners in primary care commonly offer $\mathrm{ADs}$ to patients seeking help for depressive symptoms (Sihvo et al., 2008; Vuorilehto et al., 2016). The probability to use ADs is mainly predicted by severity, duration and perceived disability associated with depression, and not by education, income, employment status, or living arrangements (Hämäläinen et al., 2004, 2009). We thus expect changes in $\mathrm{AD}$ use to accurately reflect underlying changes in depression. Previous studies have confirmed that at the time of separation, prevalence trajectories of psychotropic medication use are similar in shape compared to trajectories of psychological distress observed using survey samples (Anonymous, 2013, 2014; Raley \& Sweeney, 2020). The relevance of studying changes in $\mathrm{AD}$ use is further highlighted by their use strongly predicting other severe adverse outcomes such as disability retirement and mortality (Laaksonen et al., 2012; Moustgaard et al., 2013). 
We adjusted our analyses for the mother's age and her educational level, classified as "tertiary", "secondary", or "basic" based on the highest educational qualification. Mother's disposable income was classified into quintiles annually. Disposable income included earned income and money transfers received after taxes and tax-deductible expenses. Employment status ("employed", "unemployed", "other") was recorded based on the mother's main activity within the last week of the year. Area of residence referred to the mother's home municipality at the end of the year and was classified as "urban", "semi-urban", and "rural". To take into account the family's need of support, we recorded how many children age 12 or younger the mother had, classified as "none" (first child not yet born in the four-year pre-separation period, or already older than 12), "one", and "two or more". We also recorded the age of the youngest child. In Finland, all children enter mandatory pre-school at the age of 6 , and we thus classified the age of the youngest child as "5 years or less" vs. "6 to 12 years". The register-data had no information on custodial arrangements, so we could not measure whether the parents shared custody after separation. However, we approximated the father's involvement by measuring how close the parents lived to each other after separation. We calculated the geographical distance between postal areas of both the mother and the father and classified a living distance of less than ten kilometers as close. In addition to the child's biological father, the mother's new partner is a potential source of support. To identify new partners, we used annual information on both marital status and non-marital cohabitation. Statistics Finland defines cohabiting partners as persons living in the same dwelling and of different genders, not living with a married spouse, not being siblings, and with an age difference not exceeding 15 years, which results in quite a similar prevalence of non-marital cohabiting unions as survey samples in Finland (Anonymous, 2014). 
Mothers were linked to their youngest child's biological grandparents; that is, their own mother and father as well as their (ex-)mother-in-law and (ex-)father-in-law. We refer to one's own parents as maternal grandparents and to (ex-)parents-in-law as paternal grandparents. For each grandparent, we measured their age, employment status, health status, and distance to the mother. All grandparents' characteristics were measured at the year of separation. Age was classified as "less than 70 years" vs. "at least 70 years". Employed grandparents were separated from all other grandparents ("employed" vs. "non-employed"). Grandparents' health ("has a chronic health condition" vs. "does not have a chronic health condition") was measured using information on hospital-level care and medication purchases related to chronic conditions including dementia, stroke, Parkinson's disease and hip fracture. These conditions are associated with functional capacity and are also known to predict entry into institutional care (Nihtilä et al., 2008). Similar to non-resident fathers, distance between each grandparent and the mother was measured using postal area codes, with less than ten kilometers classified as close. Finally, we assessed whether the grandparents were living together as spouses at the time of separation or not. Although their living arrangements are not expected to affect the availability of support from the grandmother, support from the grandfather may be weaker if the grandparents are no longer living together (Danielsbacka \& Tanskanen, 2012; Kalmijn, 2007) and the overall level of support may thus be lower.

\section{Statistical Analyses}

We observed mothers' $\mathrm{AD}$ purchases four years before and four years after the exact date of separation, expecting that most changes in depression would occur within this time frame (Anonymous 2013). For each year, we identified whether at least one AD purchase had been made. 
Depression trajectories were then examined by modeling annual AD purchases - herein referred to as $\mathrm{AD}$ use - by characteristics of the grandparents, measured at the year of separation. All models were adjusted for calendar year to account for the overall increase in $\mathrm{AD}$ use, and the mothers' own characteristics, which were all time-varying covariates. The models were fitted using logistic panel regression, and we used general estimating equations to control for withinindividual correlations (Twisk, 2013). We present estimates from models that separately examine the role of each characteristic of each grandparent to mothers' AD use. We also performed two robustness checks (Supporting Material available online): 1) Because a grandparent's characteristics are intertwined - age, employment, and health in particular - we estimated models that included information on all the measured characteristics of one grandparent simultaneously. 2) We also estimated models that included information on each specific characteristic of all grandparents at the same time. These models helped to assess whether, e.g., maternal grandfather's age is related to mother's AD use only by being a proxy measure for maternal grandmother's age.

\section{Unknown and Deceased Grandparents}

In our sample where all mothers could be linked to at least one maternal or paternal grandparent of their youngest child, only $574(0.5 \%)$ mothers could not be linked to their own biological mother; that is, the maternal grandmother (Supporting Table 1). These women were clearly older than other women, reflecting the fact that a missing maternal grandmother mainly results from her being deceased before the introduction of personal identification codes in 1968. Another 2863 (2.4\%) maternal grandmothers were identified but deceased before the mother's separation. A mother's own father (the maternal grandfather) was unknown for $3.3 \%$ and deceased for $4.7 \%$ of mothers. The proportions of missing paternal grandparents were somewhat higher: $4.4 \%$ for grandmothers and $7.9 \%$ for grandfathers. Of the paternal grandparents, $3.2 \%$ of grandmothers and 
$5.4 \%$ of grandfathers were already deceased at the time of separation. Differences in mothers' characteristics by grandparent being alive, unknown, or deceased mainly resulted from the different age distributions between groups. We compared mothers' AD use by each grandparent being known or unknown (Supporting Figure 1). There were no systematic differences between mothers by whether their own mother, own father, mother-in-law, or father-in-law was known or not. Second, we compared mothers' AD use by whether a known grandparent was deceased or alive (Supporting Figure 2). Mothers whose own mother was deceased had slightly higher AD use before separation, but the difference was not statistically significant. No differences were observed by own father, mother-in-law or father-in-law being deceased or alive. Missing information on grandparents was thus unlikely to bias any of our main results, and all further analyses excluded both unknown and deceased grandparents.

\section{RESULTS}

Our total sample included 118,006 separating mothers linked to at least one grandparent (Table 1). Their mean age at separation was 33.9 years and during the first year following the date of separation, $15.7 \%$ made at least one $\mathrm{AD}$ purchase. The lowest educated and non-employed mothers had somewhat higher $\mathrm{AD}$ use than others, but differences in $\mathrm{AD}$ use by income were small. Most mothers lived in urban areas, and their AD use was somewhat higher than among other mothers. Nearly two-thirds of women had at least two children, and their youngest child was younger than six years old. Mothers of younger children had slightly lower AD use than mothers of older children (ages 6-12). Only $5 \%$ of separating mothers were living with a new partner immediately after separation, but $62.1 \%$ lived close to their youngest child's father. Interestingly, whereas having a new partner was associated with lower AD use, mothers living close to their ex-partner had higher AD use than others. 
At the time of mothers' separation, most grandparents were less than 70 years of age (Table 2), and $\mathrm{AD}$ use was higher among mothers that had older parents and parents-in-law. Among all mothers, the probability of AD use clearly increased before separation (Figure 1). During the one year's time after the exact date of separation, AD use was slightly higher than during the year immediately preceding separation, whereas it was considerably larger compared to two years before separation. During the second year following separation, AD use was similar to the year before separation, but thereafter the decline was minimal. Four years after separation, AD use had plateaued at a level clearly higher than four years before separation.

Trajectories of mothers' $\mathrm{AD}$ use were similar irrespective of paternal grandparents' age. In contrast, both own mother's and own father's age were associated with mothers' AD use. Mothers whose own mother was 70 years or older at separation already had 1.2 percentage points higher AD use 4 years before separation. This difference remained during the entire follow-up, peaking at 2.2 percentage points immediately before separation. Mothers with older fathers had very slightly higher $\mathrm{AD}$ use 4 years before separation compared to mothers whose own father was younger than 70 . Thereafter, the difference started to increase and reached 1.3 percentage points immediately before separation, before decreasing again after separation. If all grandparents were included in the same model, the importance of own father's age was further diminished (Supporting Figure 3). 
Table 1. Mothers' characteristics and antidepressant (AD) use at the year of separation; mothers with at least one living grandparent of their youngest child $(N=118,006)$

Distribution $\quad$ AD use (\%)

Mean age, years

33.9

15.7

Education, \%

Basic

18.3

16.8

Secondary

Tertiary

Employment status, \%

Employed

Unemployed

Other

Disposable income quintile, $\%$

First (lowest)

Second

Third

Fourth

Fifth (highest)

Area of residence, \%

Urban

Semi-urban

Rural

Number of children, \%

1

$2+$

Age of youngest child, \%

$0-5$

6-12

Child's father lives close, \%

Yes

No

New partner, $\%$

Yes

No
46.7

35.0

70.1

10.0

19.9

16.5

20.5

20.6

21.2

21.3

70.6

15.9

13.5

37.9

62.1

64.5

35.5

62.1

37.9

5.2

94.9
15.0

16.0

14.6

18.3

18.3

16.0

16.5

15.4

15.2

15.4

16.2

14.8

14.4

15.0

16.1

15.1

16.7

16.2

14.8

12.8

15.8 
Table 2. Grandparents' characteristics and mothers' antidepressant use at the year of separation

\begin{tabular}{|c|c|c|c|c|c|c|c|c|}
\hline & \multicolumn{2}{|c|}{$\begin{array}{l}\text { Own mother } \\
\mathrm{N}=114,569\end{array}$} & \multicolumn{2}{|c|}{$\begin{array}{l}\text { Own father } \\
\mathrm{N}=108,491\end{array}$} & \multicolumn{2}{|c|}{$\begin{array}{c}\text { Mother-in-law } \\
\mathrm{N}=109,045\end{array}$} & \multicolumn{2}{|c|}{$\begin{array}{c}\text { Father-in-law } \\
\mathrm{N}=102,266\end{array}$} \\
\hline & $\begin{array}{c}\text { Distribution } \\
(\%)\end{array}$ & $\begin{array}{l}\text { AD use } \\
(\%)\end{array}$ & $\begin{array}{c}\text { Distribution } \\
(\%)\end{array}$ & $\begin{array}{l}\text { AD use } \\
(\%)\end{array}$ & $\begin{array}{c}\text { Distribution } \\
(\%)\end{array}$ & $\begin{array}{l}\text { AD use } \\
(\%)\end{array}$ & $\begin{array}{c}\text { Distribution } \\
(\%)\end{array}$ & $\begin{array}{l}\text { AD use } \\
(\%)\end{array}$ \\
\hline \multicolumn{9}{|l|}{ Age } \\
\hline Less than 70 years & 80.7 & 15.1 & 68.5 & 15.0 & 73.3 & 15.3 & 60.9 & 15.2 \\
\hline 70 years or more & 19.3 & 17.9 & 31.5 & 17.2 & 26.8 & 16.8 & 39.2 & 16.6 \\
\hline \multicolumn{9}{|l|}{ Employed } \\
\hline Yes & 40.9 & 14.1 & 32.0 & 14.0 & 34.3 & 14.8 & 26.3 & 14.7 \\
\hline No & 59.1 & 16.7 & 68.0 & 16.5 & 65.7 & 16.1 & 73.7 & 16.1 \\
\hline \multicolumn{9}{|c|}{ Has a chronic health condition } \\
\hline Yes & 6.1 & 18.7 & 7.2 & 18.4 & 7.3 & 17.4 & 8.3 & 17.0 \\
\hline No & 93.9 & 15.5 & 92.8 & 15.4 & 92.7 & 15.5 & 91.8 & 15.6 \\
\hline \multicolumn{9}{|l|}{ Lives close to mother } \\
\hline Yes & 41.7 & 15.0 & 31.7 & 14.8 & 35.6 & 15.3 & 28.0 & 15.2 \\
\hline No & 58.3 & 16.1 & 68.3 & 16.1 & 64.5 & 15.9 & 72.1 & 15.9 \\
\hline \multicolumn{9}{|c|}{$\begin{array}{l}\text { Lives together with other biological } \\
\text { grandparent }\end{array}$} \\
\hline Yes & 43.6 & 14.9 & 46.1 & 14.9 & 43.0 & 15.5 & 46.8 & 15.5 \\
\hline No & 56.4 & 16.3 & 53.9 & 16.3 & 57.0 & 15.8 & 54.2 & 15.9 \\
\hline
\end{tabular}


FIGURE 1. MOTHERS' ANTIDEPRESSANT USE BY GRANDPARENTS' AGE
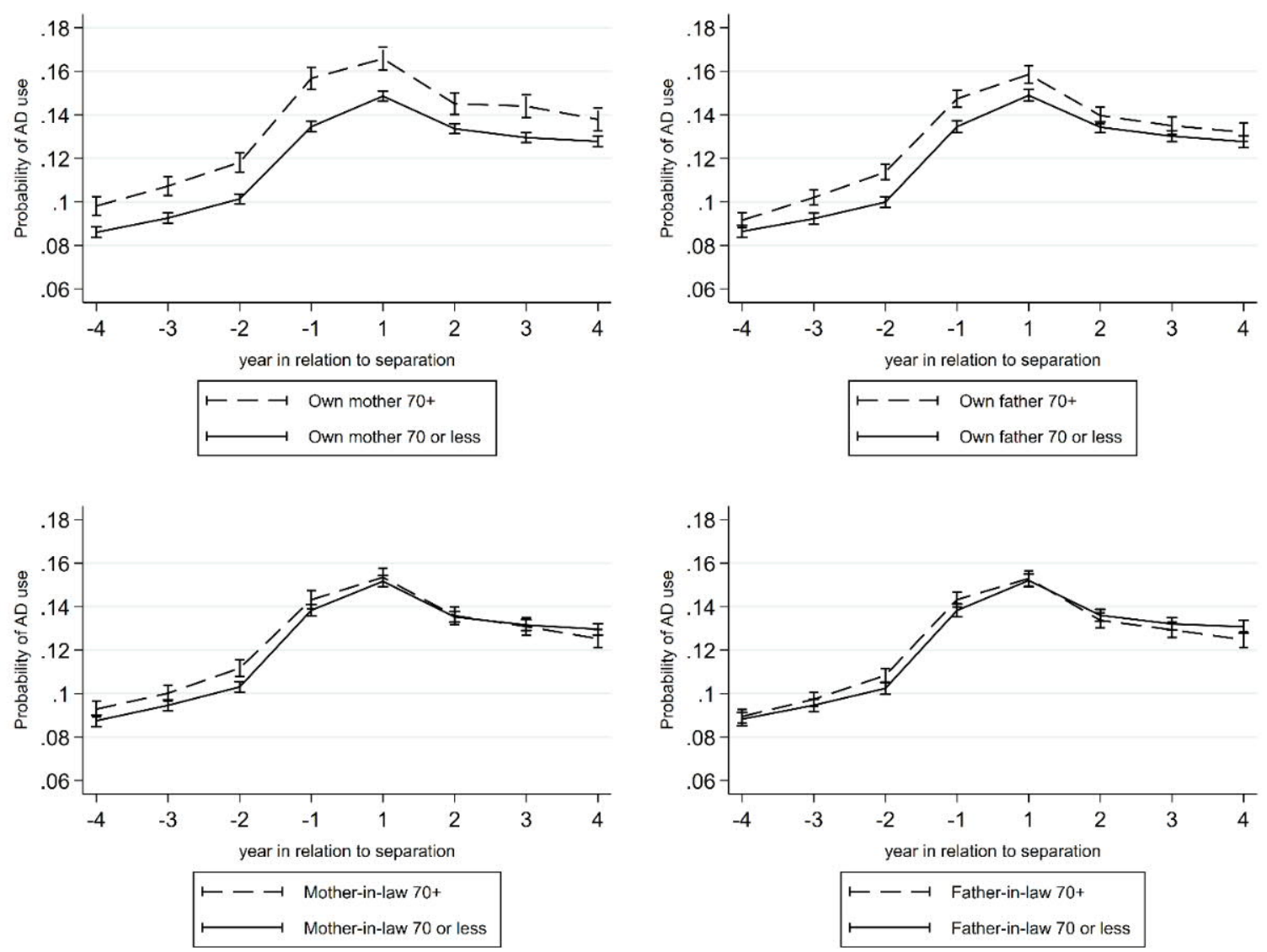

Only $41.1 \%$ of maternal grandmothers and $32.3 \%$ of maternal grandfathers were employed (Table 2). Among paternal grandparents who were on average older, the proportions were even lower. A grandparent being not employed was associated with mothers' higher AD use at the time of separation. Mothers whose own mother was employed had clearly lower AD use than other mothers throughout the follow-up (Figure 2). Changes in AD use before and after separation were similar irrespective of maternal grandmother's employment, although the difference between groups was slightly higher at the time of separation (1.7 percentage points) compared to four years before (1.0 percentage points) or four years after ( 0.9 percentage points) separation.

FIGURE 2. MOTHERS' ANTIDEPRESSANT USE BY GRANDPARENTS' EMPLOYMENT 

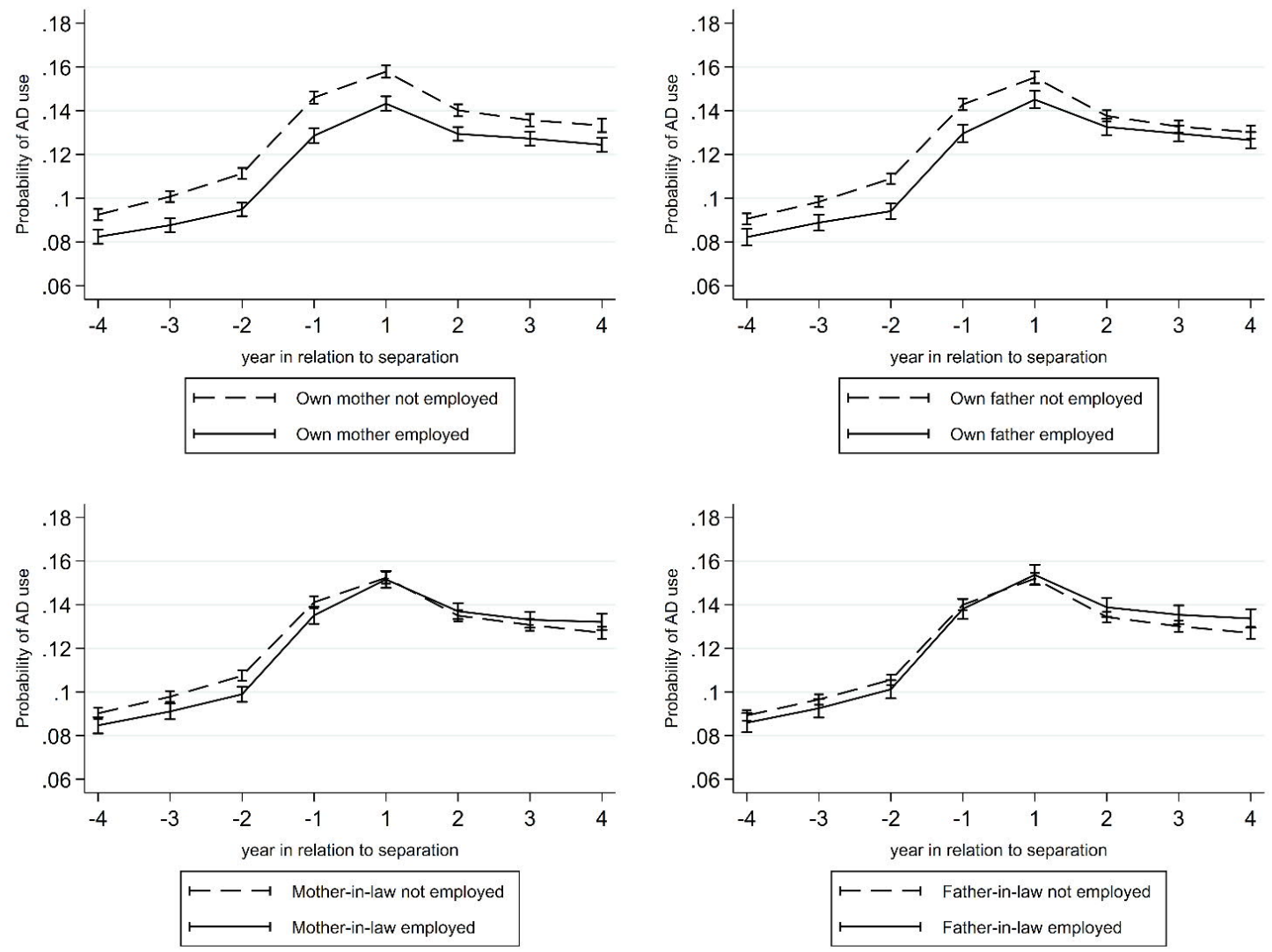

Mothers whose own father was employed also had lower (from 0.8 to 1.3 percentage points) AD use before and during separation, but three years after separation the difference had disappeared. In a model that simultaneously adjusted for each grandparent's age and employment, the association between employment and mother's AD use remained almost unchanged (Supporting Figure 7). The association between maternal grandparent's employment and mother's $\mathrm{AD}$ use thus does not result only from the employed grandparents being younger than other grandparents.

If the paternal grandmother was employed, mothers had slightly lower AD use four to two years before separation ( 0.5 to 0.8 percentage points), but the difference then diminished during the year immediately before separation before completely disappearing during the year immediately after separation. However, in a model including all grandparents at the same time, the association between paternal grandmother's employment and mother's AD use was negligible (Supporting Figure 4). The paternal grandfather's employment was not related to mothers' AD use during the follow-up. 
Chronic health conditions of dementia, stroke, Parkinson's disease or hip fracture were rather uncommon among grandparents, their prevalence ranging from $6.1 \%$ among maternal grandmothers to $8.3 \%$ among paternal grandfathers (Table 2). Both own mother's and own father's poor health was strongly related to mother's AD use (Figure 3).

\section{FIGURE 3. MOTHERS’ ANTIDEPRESSANT USE BY GRANDPARENTS’ HEALTH}
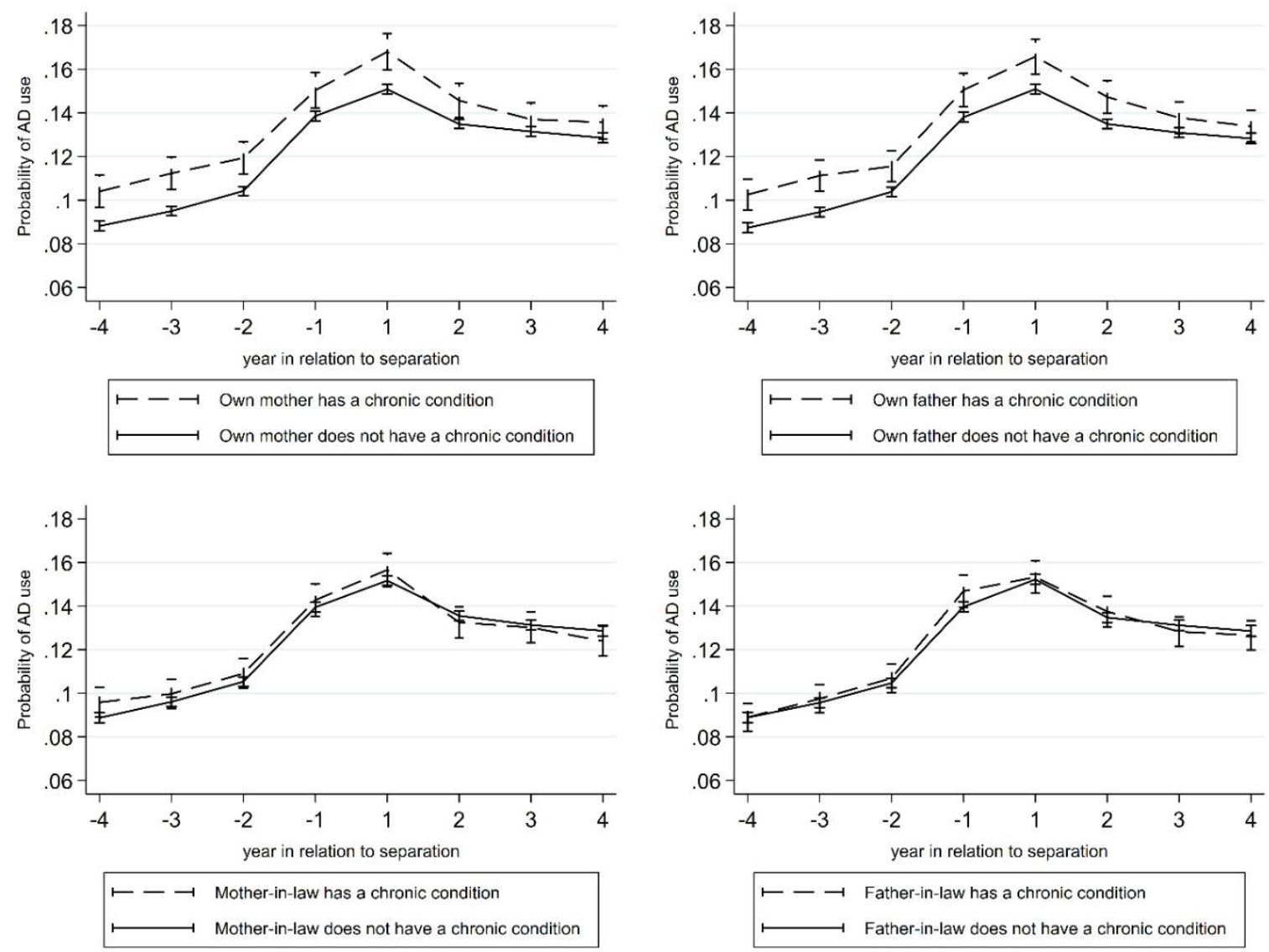

Mothers whose own parent had a chronic health condition had clearly higher AD use during the entire followup, the difference between other mothers being largest before and during separation (1.2 to 1.7 percentage points). Neither the paternal grandmothers' nor paternal grandfathers' chronic health conditions were related to mothers' $\mathrm{AD}$ use. The results were very robust to different model specifications (Supporting Figure 5, see also Supporting Figures 7 to 10$)$. 
The proportion of mothers living close to their own mother was $41.7 \%$, whereas the proportion living close to their own father was only $31.7 \%$ (Table 2). About one-third of mothers lived close to their (ex-)mother-in-law, whereas the proportion living close their (ex-)father-in-law was smaller. Living close to grandparents was clearly associated with mothers' lower AD use (Figure 4).

Before separation, distance to paternal grandparents seemed equally important compared to distance to maternal grandparents (difference in $\mathrm{AD}$ use 1.0 to 1.4 percentage points immediately before separation). However, immediately after separation mothers living close to their (ex-)parent-in-law had almost the same level of AD use as other mothers, and after separation mothers living close to their own parent continued to show clearly lower $\mathrm{AD}$ use compared to other mothers. When we estimated a model that included all grandparents (Supporting Figure 6), distance to own mother seemed to matter immediately before separation, and particularly after it. In contrast, distance to own father seemed important before separation. Distance to (ex-)father-in-law was not associated with mothers' AD use when distance to (ex-)mother-in-law was analyzed simultaneously. 


\section{FIGURE 4. MOTHERS’ ANTIDEPRESSANT USE BY DISTANCE TO EACH GRANDPARENT}
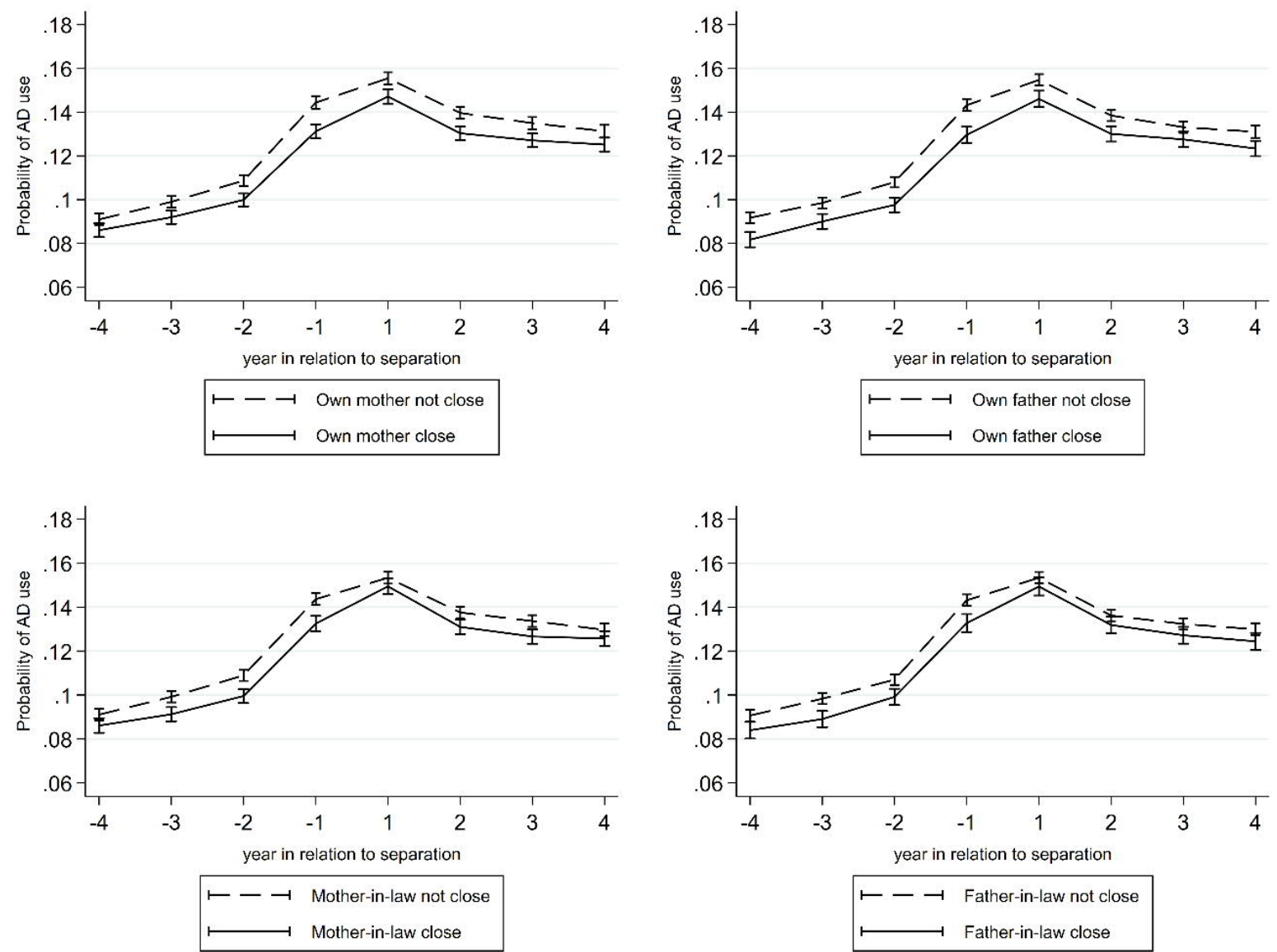

About $40 \%$ of grandmothers were living with the mother's father, whereas about $60 \%$ had either never lived together or were separated or widowed (Table 2). The proportion of grandfathers living with the grandmother was slightly higher. Mothers whose own parents were living together had clearly lower AD use compared to mothers whose own parents were not living together (Figure 5). The difference in AD use was already large four years before separation (1.2 percentage points), and although there was a modest reduction in the difference immediately before separation, four years after separation the difference was even larger than four years before separation (1.5 percentage points). Whether the (ex-)parents-in-law were living together or not was not associated with mothers' AD use.

FIGURE 5. MOTHERS’ ANTIDEPRESSANT USE BY GRANDPARENTS LIVING TOGETHER OR NOT 

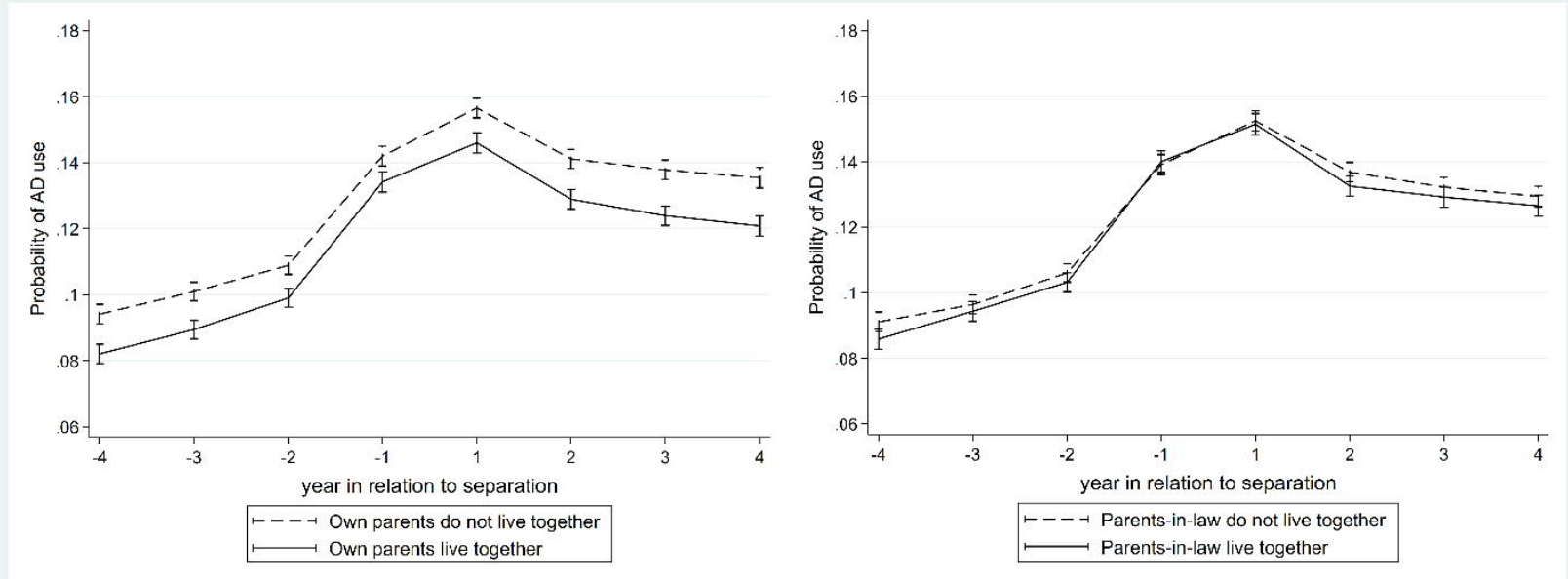

\section{DISCUSSION}

Using unique multigenerational data, this study examined trajectories of separating mothers' depression by grandparents' characteristics that indicate their availability to provide support in a life situation characterized by loss of resources. Generally, depression clearly increased before separation among all mothers, followed by a gradual decline after separation. The magnitude of these changes was associated with grandparents' characteristics that measure potential grandparental support. Mothers whose own parents did not have chronic health conditions or were younger than 70 years old at the time of separation had a lower probability of depression compared to other separating mothers. This is consistent with previous studies suggesting that younger grandparents in good health are more likely than other grandparents to provide support and childcare (Aassve et al., 2012). Furthermore, having an old and frail grandparent may even place an additional burden on separating mothers who, instead of receiving support, need to provide support upward (Margolis \& Wright, 2017). Hence, generally, our findings corroborate the predictions from COR theory that potential support from grandparents may partially compensate for resource losses related to the separation process.

Interestingly, the differences in mothers' probability of depression by grandparental age and health were even larger before separation than after. Although depression increased while approaching separation, we did not observe an exacerbation of the mothers' pre-existing differences in depression. Contradicting our theoretical predictions, somewhat faster declines in depression were observed after separation among mothers with older and frail grandparents. We can speculate that grandparental support reduced depression related to intra-couple 
conflicts during the years preceding separation, but did not speed up mothers' recovery following the separation. The finding is in line with a previous Finnish study that found clear pre-divorce differences in mental health by individuals' own social and economic resources, but also showed that these resources were mainly unrelated to changes in mental health during and after the separation process (Anonymous, 2013). These findings add to the growing evidence that the long-term effects of adverse life-course events within families are not necessarily stronger among the more disadvantaged population subgroups, where the overall level of family resources is lower and there are thus fewer resources to lose (Barclay \& Hällsten, 2021; Bernardi \& Boertien, 2016). It is also possible that following separation grandparental involvement may actually be harmful. Parent-grandparent relationships are often characterized by ambivalence, and family transitions such as separation may alter the balance between positive and negative emotions (Zartler et al., 2020). After separation, a higher level of grandparental involvement may thus be a further source of conflict and stress for some mothers (Greenfield, 2011), which may contribute to a slower decline of depression among them.

We also found that the probability of mothers' depression was lower if grandparents were still employed, suggesting that grandparental employment does not necessarily hinder provision of informal support to younger generations. Employed grandparents are less likely to be in need of support themselves, and the income from paid work could also increase their probability to provide material support to their children and grandchildren independent of the mothers' own resources. Nevertheless, from the perspective of policy attempts that aim to prolong working lives, it is important to note that grandparents' employment is not associated with an increased risk of separating mothers' depression.

Interestingly, before separation, distance to paternal grandparents seemed equally important compared to distance to maternal grandparents. However, during the separation process mothers living close to a paternal grandparent showed a higher increase in the probability of depression, and immediately after separation living close to a paternal grandparent showed no advantage over not living close to a paternal grandparent. Although grandparents living close may in general offer more support than grandparents not living close (Hank, 2007; Heylen et al., 2012), this may not hold at a time of conflict. The custodial mother may exercise control over paternal 
grandparents' involvement (Albertini \& Tosi, 2018; Douglas \& Ferguson, 2003), which may exacerbate conflicts and lead to less support from the paternal grandparents. However, after the first year of separation mothers living close to a paternal grandparent again had a lower probability of depression than mothers not living close. This may either mean that the period of conflict immediately before separation is particularly stressful for mothers living close to a paternal grandparent, or that it is the anticipation of future support that matters (Hobfoll, 2001). The largest differences in mothers' level of depression were observed by maternal grandparents' characteristics. However, we did not find support for the idea that the importance of maternal grandparents for mothers' depression would increase after separation. It is possible that the mothers in our sample maintain closer contacts with their own parents after separation as suggested by previous studies (Jappens \& Bavel, 2016; Westphal et al., 2015), but these closer contacts do not protect them from depression. Of the maternal grandparents, it was the grandmother that seemed more important for mothers' depression. However, although maternal grandmother's age seemed to matter more than maternal grandfather's age, both maternal grandmother's and grandfather's health were equally important predictors of the mother's depression. Thus, separating mothers may need to provide upward care and support to their own ill parent irrespective of that parent's gender, whereas it is more often the mother's own mother than father that provides care downward (Margolis \& Wright, 2017).

Our results also showed that mothers whose own parents were still living together at the time of the mother's own separation had lower levels of depression compared to other mothers. Whereas the grandmother's propensity to provide support is only weakly - if at all - associated with her partnership status, grandfathers who are not partnered are less likely to provide support to their adult children and grandchildren (Hank \& Buber, 2008; Kalmijn, 2007). Thus, grandparents whose own union is still intact are the ones most likely to provide support to their children and grandchildren, and this high level of support could partly explain mothers' lower probability of depression. Our results confirm this pattern, indicating that single mothers who themselves had experienced parental divorce are a particularly vulnerable group. Given insights from the literature on intergenerational transmission of divorce (Amato \& DeBoer, 2001), women with separated parents are overrepresented among 
single mothers and at the same time they are more likely to be disadvantaged when it comes to access to grandparental support.

Our study has a number of findings that are relevant for understanding how negative life-course events, such as separation, shape trajectories of mental health, but it is not without limitations. Although we were able to measure several characteristics of both the maternal and paternal grandparents, our dataset had no direct measure of grandparental support. We do not know how often grandparents provide childcare and how involved they are in the lives of their separating children and grandchildren. However, when examining associations at the population level, we argue that well-established predictors of grandparental support may be used to estimate the average amount of support available to adult children and grandchildren. As expectations of grandparental support are known to affect, e.g., fertility intentions (Rutigliano, 2020), it may well be that separating mothers' mental wellbeing also depends on the expectation of support at a time of need rather than the support that is actually received. We also had no direct information on custodial arrangements after separation, but we approximated father's involvement by the geographical distance between the separated parents. Because the child's school or daycare center is in most cases determined by the resident parent's address, the father needs to live relatively close to actively participate in the everyday lives of his children. We also have no reason to expect that our incomplete measurement of fathers' involvement would in any way bias our results regarding grandparental support. To take advantage of the register linkage between biological relatives, we also had to restrict our sample to native-born mothers. In Finland as in other European countries, it is important for future research to study the level of grandparental support among the increasing number of families with immigrant backgrounds.

Nevertheless, our results shed light on how access to informal support exchanged between generations may not only reduce single mothers' mental health disadvantage, but potentially also affects the mental health of mothers while they still live in intact unions. Future studies should examine in more detail how the downward and upward transfers of support shape the mental health of the "sandwich generation", which is more likely than previous generations to experience union instability and complex family forms, while still having multiple living parents. 
Overall, our study corroborates the expectations from COR theory that potential support from grandparents may partially compensate for the anticipated or experienced resource losses related to separation. Our study suggests that potential support from social networks may matter for mothers' mental health even in the context of a Nordic welfare state, where all parents - including single parents - benefit from generous institutional support. Our study also has important implications for research on children's wellbeing in families of single mothers. In many countries, an increasing proportion of children are living with separated mothers (Bernardi et al., 2018). Maternal depression may affect parenting and family functioning, and modest, but robust, associations between maternal depression and adverse child behavioral and emotional outcomes are well-established in the literature (Goodman et al., 2011). Such cross-over effects on children underline the importance of better understanding the emergence and course of maternal depression, and the role of potential mitigating factors such as support from extended family. 


\section{REFERENCES}

Aassve, A., Meroni, E., \& Pronzato, C. (2012). Grandparenting and Childbearing in the Extended Family. European Journal of Population / Revue Européenne de Démographie, 28(4), 499-518. https://doi.org/10.1007/s10680-012-9273-2

Albertini, M., \& Tosi, M. (2018). Grandparenting after parental divorce: The association between non-resident parent-child meetings and grandparenting in Italy. European Journal of Ageing, 15(3), 277-286. https://doi.org/10.1007/s10433-018-0478-z

Amato, P. R. (2010). Research on Divorce: Continuing Trends and New Developments. Journal of Marriage and Family, 72(3), 650-666. https://doi.org/10.1111/j.1741-3737.2010.00723.x

Amato, P. R., \& DeBoer, D. D. (2001). The Transmission of Marital Instability Across Generations: Relationship Skills or Commitment to Marriage? Journal of Marriage and Family, 63(4), 1038-1051. https://doi.org/10.1111/j.1741-3737.2001.01038.x

Attias-Donfut, C., Ogg, J., \& Wolff, F.-C. (2005). European patterns of intergenerational financial and time transfers. European Journal of Ageing, 2(3), 161-173. https://doi.org/10.1007/s10433-005-0008-7

Barclay, K., \& Hällsten, M. (2021). Does the impact of parental death vary by parental socioeconomic status? A study of children's educational and occupational attainment. Journal of Marriage and Family, 1-24. https://doi.org/10.1111/jomf.12786

Bernardi, F., \& Boertien, D. (2016). Understanding Heterogeneity in the Effects of Parental Separation on Educational Attainment in Britain: Do Children from Lower Educational Backgrounds Have Less to Lose? European Sociological Review, 32(6), 807-819. https://doi.org/10.1093/esr/jcw036

Bernardi, L., \& Larenza, O. (2018). Variety of Transitions into Lone Parenthood. In L. Bernardi \& D. Mortelmans (Eds.), Lone Parenthood in the Life Course (pp. 93-108). Springer International Publishing. https://doi.org/10.1007/978-3-319-63295-7_5 
Bernardi, L., Mortelmans, D., \& Larenza, O. (2018). Changing Lone Parents, Changing Life Courses. In L. Bernardi \& D. Mortelmans (Eds.), Lone Parenthood in the Life Course (pp. 1-26). Springer International Publishing. https://doi.org/10.1007/978-3-319-63295-7_1

Bucx, F., Wel, F. van, \& Knijn, T. (2012). Life Course Status and Exchanges of Support Between Young Adults and Parents. Journal of Marriage and Family, 74(1), 101-115. https://doi.org/10.1111/j.17413737.2011.00883.x

Cooney, T. M. (2020). Grandparents' Support to Young Families: Variations by Adult Children's Union Status $\dagger$. Journal of Marriage and Family. https://doi.org/10.1111/jomf.12728

Cooper, C., Bebbington, P. E., Meltzer, H., Bhugra, D., Brugha, T., Jenkins, R., Farrell, M., \& King, M. (2008). Depression and common mental disorders in lone parents: Results of the 2000 National Psychiatric Morbidity Survey. Psychological Medicine, 38(3), 335-342.

https://doi.org/10.1017/S0033291707001493

Danielsbacka, M., \& Tanskanen, A. O. (2012). Adolescent grandchildren's perceptions of grandparents' involvement in UK: An interpretation from life course and evolutionary theory perspective. European Journal of Ageing, 9(4), 329-341. https://doi.org/10.1007/s10433-012-0240-x

Danielsbacka, M., \& Tanskanen, A. O. (2018). Marital disruption and intergenerational relations among older Finns. Contemporary Social Science, 13(2), 203-218. https://doi.org/10.1080/21582041.2017.1422794 Danielsbacka, M., Tanskanen, A. O., Jokela, M., \& Rotkirch, A. (2011). Grandparental Child Care in Europe: Evidence for Preferential Investment in More Certain Kin. Evolutionary Psychology, 9(1), 147470491100900100. https://doi.org/10.1177/147470491100900102

Douglas, G., \& Ferguson, N. (2003). The Role of Grandparents in Divorced Families. International Journal of Law, Policy and the Family, 17(1), 41-67. https://doi.org/10.1093/lawfam/17.1.41

Drew, L. M., \& Silverstein, M. (2007). Grandparents’ psychological well-being after loss of contact with their grandchildren. Journal of Family Psychology: JFP: Journal of the Division of Family Psychology of the 
American Psychological Association (Division 43), 21(3), 372-379. https://doi.org/10.1037/08933200.21.3.372

Dunifon, R. E., Near, C. E., \& Ziol-Guest, K. M. (2018). Backup Parents, Playmates, Friends: Grandparents’ Time With Grandchildren. Journal of Marriage and Family, 80(3), 752-767. https://doi.org/10.1111/jomf.12472

Dziak, E., Janzen, B. L., \& Muhajarine, N. (2010). Inequalities in the psychological well-being of employed, single and partnered mothers: The role of psychosocial work quality and work-family conflict. International Journal for Equity in Health, 9(1), 6. https://doi.org/10.1186/1475-9276-9-6

Goodman, S. H., Rouse, M. H., Connell, A. M., Broth, M. R., Hall, C. M., \& Heyward, D. (2011). Maternal Depression and Child Psychopathology: A Meta-Analytic Review. Clinical Child and Family Psychology Review, 14(1), 1-27. https://doi.org/10.1007/s10567-010-0080-1

Greenfield, E. A. (2011). Grandparent Involvement and Parenting Stress among Nonmarried Mothers of Young Children. Social Service Review, 85(1), 135-157. https://doi.org/10.1086/658395

Hämäläinen, J., Isometsä, E., Laukkala, T., Kaprio, J., Poikolainen, K., Heikkinen, M., Lindeman, S., \& Aro, H. (2004). Use of health services for major depressive episode in Finland. Journal of Affective Disorders, 79(1), 105-112. https://doi.org/10.1016/S0165-0327(02)00342-7

Hämäläinen, J., Isometsä, E., Sihvo, S., Kiviruusu, O., Pirkola, S., \& Lönnqvist, J. (2009). Treatment of major depressive disorder in the Finnish general population. Depression and Anxiety, 26(11), 1049-1059. https://doi.org/10.1002/da.20524

Hank, K. (2007). Proximity and Contacts Between Older Parents and Their Children: A European Comparison. Journal of Marriage and Family, 69(1), 157-173. https://doi.org/10.1111/j.1741-3737.2006.00351.x

Hank, K., \& Buber, I. (2008). Grandparents Caring for their Grandchildren: Findings From the 2004 Survey of Health, Ageing, and Retirement in Europe. Journal of Family Issues. https://doi.org/10.1177/0192513X08322627 
Harknett, K., \& Knab, J. (2007). More Kin, Less Support: Multipartnered Fertility and Perceived Support Among Mothers. Journal of Marriage and Family, 69(1), 237-253. https://doi.org/10.1111/j.17413737.2006.00356.x

Henderson, C. E., Bert Hayslip, jr, Sanders, L. M., \& Louden, L. (2009). Grandmother-Grandchild Relationship Quality Predicts Psychological Adjustment Among Youth From Divorced Families: Journal of Family Issues. https://doi.org/10.1177/0192513X09334913

Heylen, L., Mortelmans, D., Hermans, M., \& Boudiny, K. (2012). The intermediate effect of geographic proximity on intergenerational support: A comparison of France and Bulgaria. Demographic Research, 27, 455-486. JSTOR.

Hobfoll, S. E. (2001). The Influence of Culture, Community, and the Nested-Self in the Stress Process: Advancing Conservation of Resources Theory. Applied Psychology, 50(3), 337-421. https://doi.org/10.1111/1464-0597.00062

Hobfoll, S. E. (2002). Social and Psychological Resources and Adaptation. Review of General Psychology, 6(4), 307-324. https://doi.org/10.1037/1089-2680.6.4.307

Jappens, M., \& Bavel, J. V. (2016). Parental Divorce, Residence Arrangements, and Contact Between Grandchildren and Grandparents. Journal of Marriage and Family, 78(2), 451-467. https://doi.org/10.1111/jomf.12275

Kalil, A., Spencer, M. S., Spieker, S. J., \& Gilchrist, L. D. (1998). Effects of Grandmother Coresidence and Quality of Family Relationships on Depressive Symptoms in Adolescent Mothers. Family Relations, 47(4), 433-441. JSTOR. https://doi.org/10.2307/585274

Kalmijn, M. (2007). Gender Differences in the Effects of Divorce, Widowhood and Remarriage on Intergenerational Support: Does Marriage Protect Fathers? Social Forces, 85(3), 1079-1104. https://doi.org/10.1353/sof.2007.0043 
Kamp Dush, C. M. (2013). Marital and Cohabitation Dissolution and Parental Depressive Symptoms in Fragile Families. Journal of Marriage and Family, 75(1), 91-109. https://doi.org/10.1111/j.17413737.2012.01020.x

Laaksonen, M., Metsä-Simola, N., Martikainen, P., Pietiläinen, O., Rahkonen, O., Gould, R., Partonen, T., \& Lahelma, E. (2012). Trajectories of mental health before and after old-age and disability retirement: A register-based study on purchases of psychotropic drugs. Scandinavian Journal of Work, Environment \& Health, 38(5), 409-417. https://doi.org/10.5271/sjweh.3290

Margolis, R., \& Wright, L. (2017). Healthy Grandparenthood: How Long Is It, and How Has It Changed? Demography, 54(6), 2073-2099. https://doi.org/10.1007/s13524-017-0620-0

Min, J., Johnson, M. D., Anderson, J. R., \& Yurkiw, J. (2021). Support exchanges between adult children and their parents across life transitions. Journal of Marriage and Family, 1-26. https://doi.org/10.1111/jomf.12787

Moustgaard, H., Joutsenniemi, K., Sihvo, S., \& Martikainen, P. (2013). Alcohol-related deaths and social factors in depression mortality: A register-based follow-up of depressed in-patients and antidepressant users in Finland. Journal of Affective Disorders, 148(2), 278-285. https://doi.org/10.1016/j.jad.2012.12.008

Nihtilä, E. K., Martikainen, P. T., Koskinen, S. V. P., Reunanen, A. R., Noro, A. M., \& Häkkinen, U. T. (2008). Chronic conditions and the risk of long-term institutionalization among older people. European Journal of Public Health, 18(1), 77-84. https://doi.org/10.1093/eurpub/ckm025

Piontak, J. R. (2016). Household Composition and Maternal Depression: Examining the Role of Multigenerational Households. Ues, 37(7), 947-969.

Radey, M., \& McWey, L. M. (2019). Informal Networks of Low-Income Mothers: Support, Burden, and Change. Journal of Marriage and Family, 81(4), 953-967. https://doi.org/10.1111/jomf.12573

Raley, R. K., \& Sweeney, M. M. (2020). Divorce, Repartnering, and Stepfamilies: A Decade in Review. Journal of Marriage and the Family, 82(1), 81-99. 
Rutigliano, R. (2020). Counting on Potential Grandparents? Adult Children's Entry Into Parenthood Across European Countries. Demography, 57(4), 1393-1414. https://doi.org/10.1007/s13524-020-00890-8

Sihvo, S., Isometsä, E., Kiviruusu, O., Hämäläinen, J., Suvisaari, J., Perälä, J., Pirkola, S., Saarni, S., \& Lönnqvist, J. (2008). Antidepressant utilisation patterns and determinants of short-term and nonpsychiatric use in the Finnish general adult population. Journal of Affective Disorders, 110(1-2), 94105. https://doi.org/10.1016/j.jad.2008.01.012

Sund, R., Gissler, M., Hakulinen, T., \& Rosén, M. (2014). Use of Health Registers. In W. Ahrens \& I. Pigeot (Eds.), Handbook of Epidemiology (pp. 707-730). Springer. https://doi.org/10.1007/978-0-387-09834$0 \_5$

Taylor, Z. E., \& Conger, R. D. (2017). Promoting Strengths and Resilience in Single-Mother Families. Child Development, 88(2), 350-358. https://doi.org/10.1111/cdev.12741

Thomese, G., \& Liefbroer, A. C. (2013). Child Care and Child Births: The Role of Grandparents in the Netherlands. Journal of Marriage and Family. https://onlinelibrary.wiley.com/doi/full/10.1111/jomf.12005

Twisk, J. W. R. (2013). Applied Longitudinal Data Analysis for Epidemiology: A Practical Guide. Cambridge University Press.

Vuorilehto, M. S., Melartin, T. K., Riihimäki, K., \& Isometsä, E. T. (2016). Pharmacological and psychosocial treatment of depression in primary care: Low intensity and poor adherence and continuity. Journal of Affective Disorders, 202(Supplement C), 145-152. https://doi.org/10.1016/j.jad.2016.05.035

Westphal, S. K., Poortman, A.-R., \& Lippe, T. V. der. (2015). What About the Grandparents? Children's Postdivorce Residence Arrangements and Contact With Grandparents. Journal of Marriage and Family, 77(2), 424-440. https://doi.org/10.1111/jomf.12173

Zartler, U., Schmidt, E.-M., Schadler, C., Rieder, I., \& Richter, R. (2020). “A Blessing and a Curse” Couples Dealing with Ambivalence Concerning Grandparental Involvement During the Transition to 
Parenthood-A Longitudinal Study. Journal of Family Issues, 0192513X20950786. https://doi.org/10.1177/0192513X20950786 


\section{Supplementary Materials}

Supporting Table 1. Mothers' characteristics at the year of separation by grandparents' being alive, unknown, or deceased; mothers linked to at least one grandparent $(N=11,006)$

$\mathrm{N}$

Mean age, years

Education, \%

$$
\begin{aligned}
& \text { Basic } \\
& \text { Secondary } \\
& \text { Tertiary }
\end{aligned}
$$

Employment status, \%

Employed

Unemployed

Other

Disposable income quintile, $\%$

First

Second

Third

Fourth

Fifth

Area of residence, $\%$

$$
\begin{aligned}
& \text { Urban } \\
& \text { Semi-urban } \\
& \text { Rural }
\end{aligned}
$$

Number of children, \%

$$
1
$$

$2+$

Age of youngest child, \%

$$
\begin{aligned}
& 0-5 \\
& 6-12
\end{aligned}
$$

Child's father lives close, $\%$

Yes

\begin{tabular}{|c|c|c|c|c|c|c|c|c|c|c|c|c|}
\hline \multirow[b]{2}{*}{ ALL } & & & & \\
\hline & Alive & Unknown & Deceased & Alive & Unnkown & Deceased & Alive & Unknown & Deceased & Alive & Unknown & Deceased \\
\hline 118,006 & 114,569 & 574 & 2,863 & 108,491 & 3,920 & 5,595 & 109,045 & 5,235 & 3,726 & 102,266 & 9,375 & 6,365 \\
\hline 100.0 & 97.1 & 0.5 & 2.4 & 91.9 & 3.3 & 4.7 & 92.4 & 4.4 & 3.2 & 86.7 & 7.9 & 5.4 \\
\hline 33.9 & 33.7 & 44.5 & 38.5 & 33.6 & 37.4 & 36.6 & 33.7 & 36.1 & 37.2 & 33.6 & 35.7 & 35.8 \\
\hline 18.3 & 18.3 & 24.0 & 15.9 & 18.1 & 25.8 & 17.3 & 18.5 & 16.3 & 16.3 & 18.3 & 19.2 & 16.4 \\
\hline 46.7 & 46.7 & 46.2 & 48.6 & 46.7 & 47.0 & 47.3 & 46.9 & 44.5 & 46.4 & 46.9 & 45.5 & 46.8 \\
\hline 35.0 & 35.0 & 29.8 & 35.5 & 35.2 & 27.2 & 35.4 & 34.7 & 39.2 & 37.3 & 34.8 & 35.3 & 36.8 \\
\hline 70.1 & 69.9 & 75.3 & 73.8 & 70.0 & 67.6 & 72.8 & 70.2 & 65.3 & 73.6 & 70.2 & 66.6 & 72.9 \\
\hline 10.0 & 10.0 & 13.9 & 11.2 & 9.9 & 13.1 & 10.8 & 9.9 & 10.9 & 11.1 & 9.9 & 11.1 & 10.4 \\
\hline 19.9 & 20.1 & 10.8 & 15.0 & 20.2 & 19.3 & 16.4 & 19.3 & 23.8 & 15.3 & 19.9 & 22.4 & 16.7 \\
\hline 16.5 & 16.6 & 9.4 & 12.6 & 16.7 & 14.1 & 14.3 & 16.7 & 15.1 & 13.7 & 16.8 & 14.6 & 13.7 \\
\hline 20.5 & 20.7 & 15.7 & 16.4 & 20.7 & 19.4 & 18.8 & 20.6 & 20.5 & 17.7 & 20.6 & 20.4 & 19.8 \\
\hline 20.6 & 20.6 & 19.9 & 21.0 & 20.6 & 20.5 & 20.5 & 20.6 & 19.8 & 20.3 & 20.6 & 20.2 & 20.4 \\
\hline 21.2 & 21.0 & 25.5 & 24.4 & 21.0 & 23.2 & 22.4 & 21.1 & 20.3 & 22.6 & 21.0 & 20.9 & 22.6 \\
\hline 21.3 & 21.2 & 29.5 & 25.6 & 21.1 & 22.7 & 23.9 & 21.0 & 24.4 & 25.7 & 20.9 & 24.0 & 23.6 \\
\hline 70.6 & 70.7 & 65.0 & 67.2 & 70.6 & 72.4 & 68.8 & 70.1 & 83.1 & 68.4 & 70.0 & 78.4 & 68.1 \\
\hline 15.9 & 15.9 & 16.0 & 17.0 & 15.9 & 14.7 & 16.1 & 16.2 & 0.3 & 16.3 & 16.3 & 11.8 & 16.5 \\
\hline 13.5 & 13.4 & 19.0 & 15.8 & 13.4 & 12.9 & 15.2 & 13.7 & 7.7 & 15.4 & 13.7 & 9.8 & 15.5 \\
\hline 37.9 & 38.0 & 36.8 & 31.9 & 38.2 & 34.7 & 33.8 & 37.8 & 42.2 & 33.7 & 38.0 & 38.9 & 34.3 \\
\hline 62.1 & 62.0 & 63.2 & 68.1 & 61.8 & 65.4 & 66.2 & 62.2 & 57.8 & 66.3 & 62.0 & 61.1 & 65.7 \\
\hline 64.5 & 65.2 & 26.0 & 45.6 & 65.5 & 51.3 & 54.1 & 65.0 & 65.4 & 49.5 & 65.2 & 62.2 & 56.2 \\
\hline 35.5 & 34.8 & 74.0 & 54.1 & 34.5 & 48.7 & 46.0 & 35.0 & 34.6 & 50.5 & 34.8 & 37.8 & 43.8 \\
\hline 62.1 & 62.0 & 61.5 & 64.1 & 62.1 & 62.4 & 62.7 & 62.5 & 54.7 & 62.0 & 62.5 & 57.2 & 62.8 \\
\hline 37.9 & 38.0 & 38.5 & 35.9 & 38.0 & 37.6 & 37.3 & 37.5 & 45.3 & 38.0 & 37.5 & 42.9 & 37.2 \\
\hline 5.2 & 5.2 & 5.1 & 3.7 & 5.2 & 4.9 & 4.5 & 5.3 & 3.1 & 4.7 & 5.3 & 3.7 & 4.7 \\
\hline 94.9 & 94.8 & 95.0 & 96.3 & 94.8 & 95.1 & 95.5 & 94.7 & 96.9 & 95.3 & 94.7 & 96.3 & 95.3 \\
\hline
\end{tabular}

No

New partner, \%

$$
\text { Yes }
$$

No

Own mother

Own father

Mother-in-law

Father-in-law 


\section{SUPPORTING FIGURE 1. MOTHERS' ANTIDEPRESSANT USE BY EACH GRANDPARENT BEING}

\section{KNOWN OR NOT}
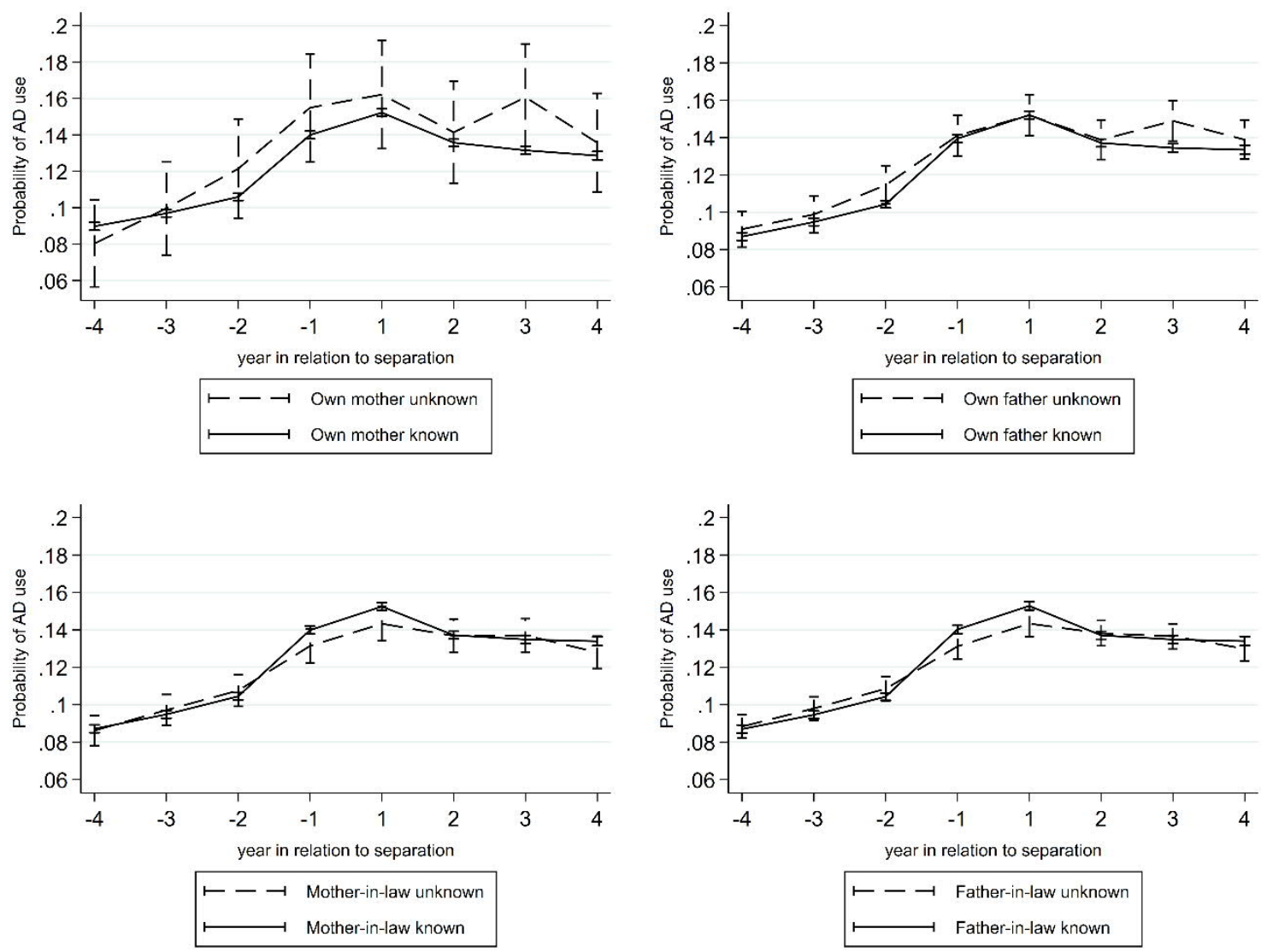

Adjusted for all mother's characteristics: age, calendar year, education, disposable income, employment status, municipality group, number of children, age of youngest child, living distance to youngest child's father, and repartnering 


\section{SUPPORTING FIGURE 2. MOTHERS’ANTIDEPRESSANT USE BY EACH GRANDPARENT BEING}

\section{ALIVE OR DECEASED}
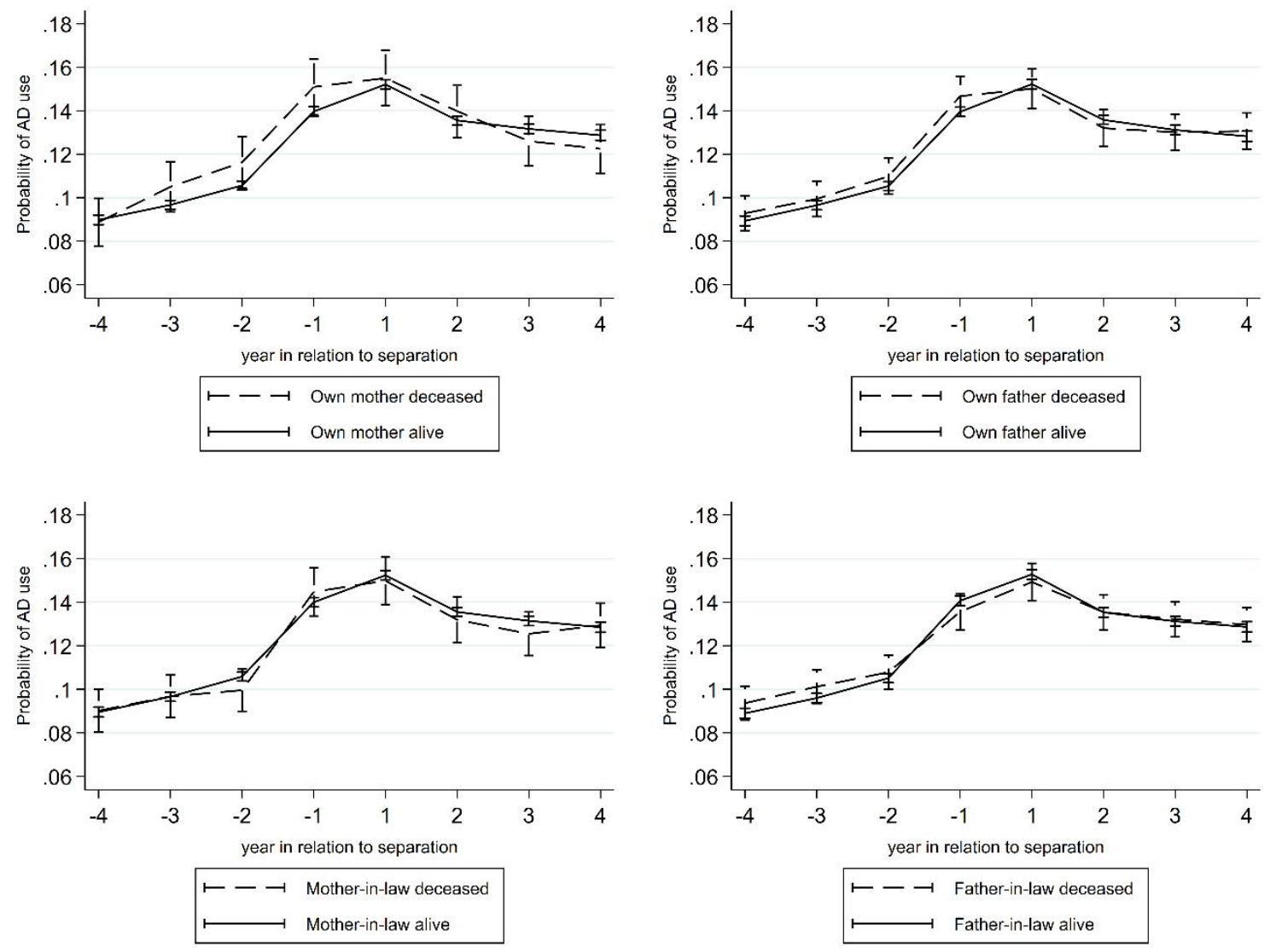

Adjusted for all mother's characteristics: age, calendar year, education, disposable income, employment status, municipality group, number of children, age of youngest child, living distance to youngest child's father, and repartnering 
SUPPORTING FIGURE 3. MOTHERS’ ANTIDEPRESSANT USE BY GRANDPARENTS’ AGE AT SEPARATION; ALL LIVING GRANDPARENTS IN THE SAME MODEL
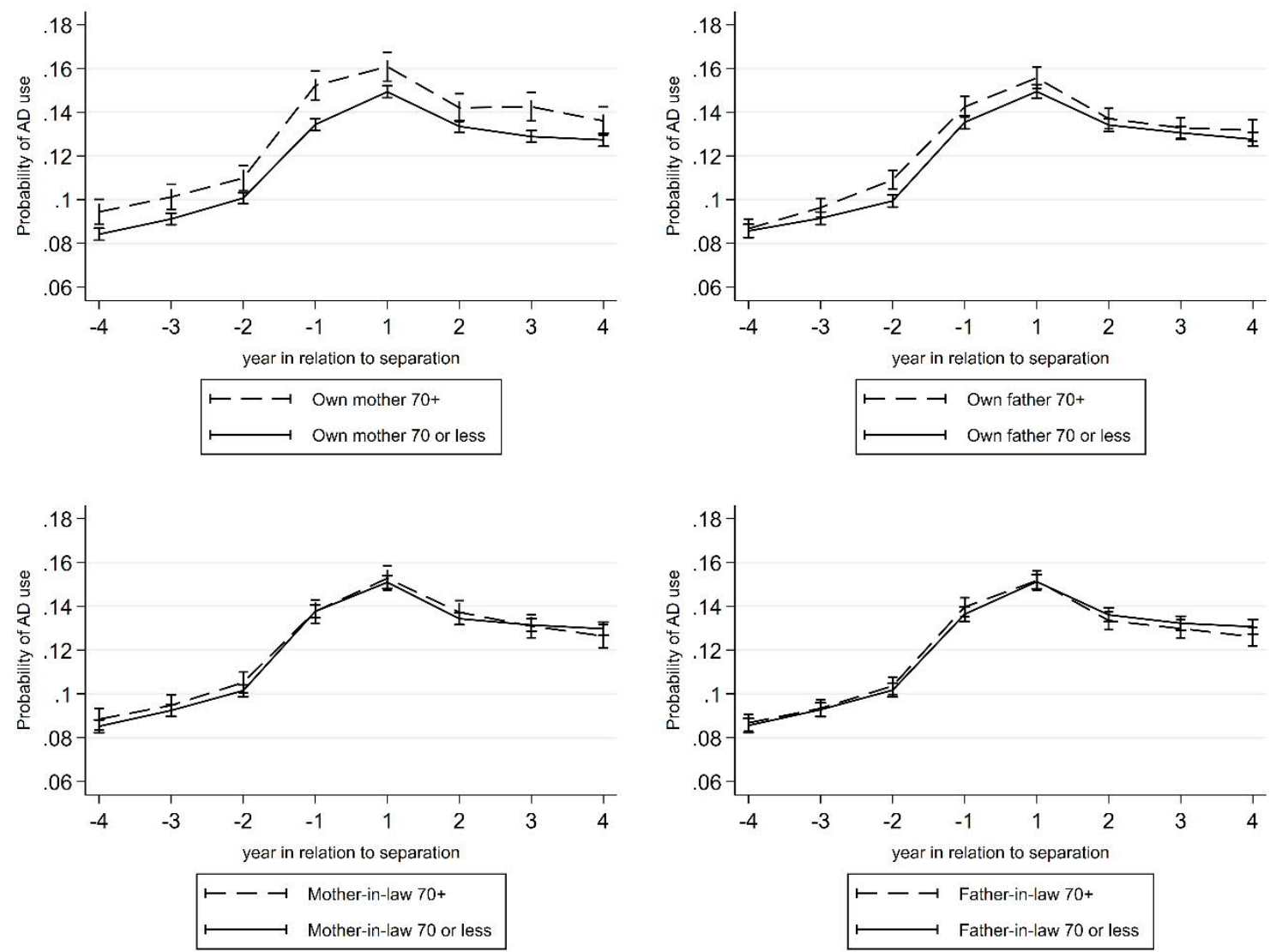

Adjusted for all mother's characteristics: age, calendar year, education, disposable income, employment status, municipality group, number of children, age of youngest child, living distance to youngest child's father, and repartnering 
SUPPORTING FIGURE 4. MOTHERS' ANTIDEPRESSANT USE BY GRANDPARENTS' EMPLOYMENT AT SEPARATION; ALL LIVING GRANDPARENTS IN THE SAME MODEL
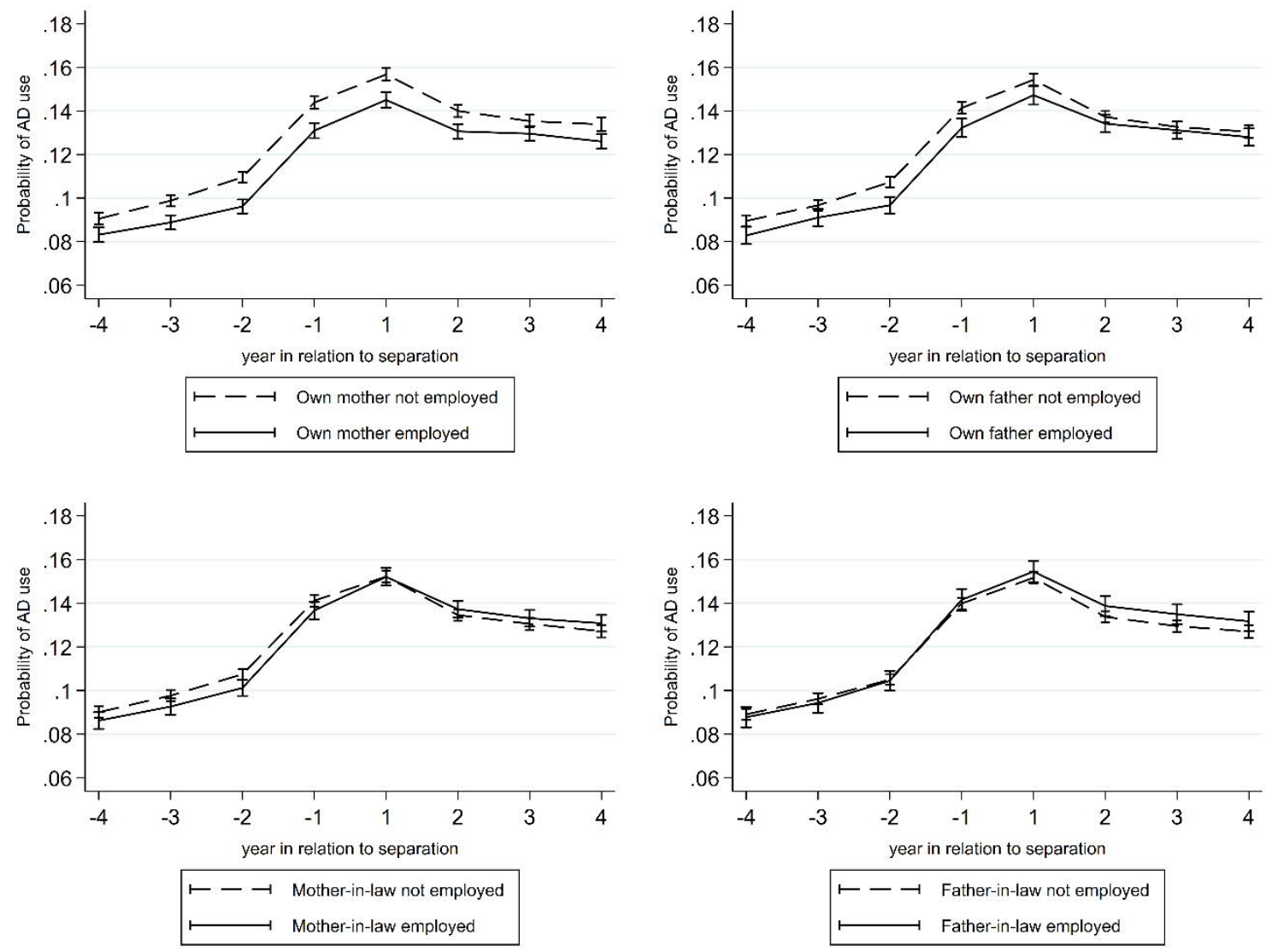

Adjusted for all mother's characteristics: age, calendar year, education, disposable income, employment status, municipality group, number of children, age of youngest child, living distance to youngest child's father, and repartnering 
SUPPORTING FIGURE 5. MOTHERS' ANTIDEPRESSANT USE BY GRANDPARENTS' HEALTH AT SEPARATION; ALL LIVING GRANDPARENTS IN THE SAME MODEL
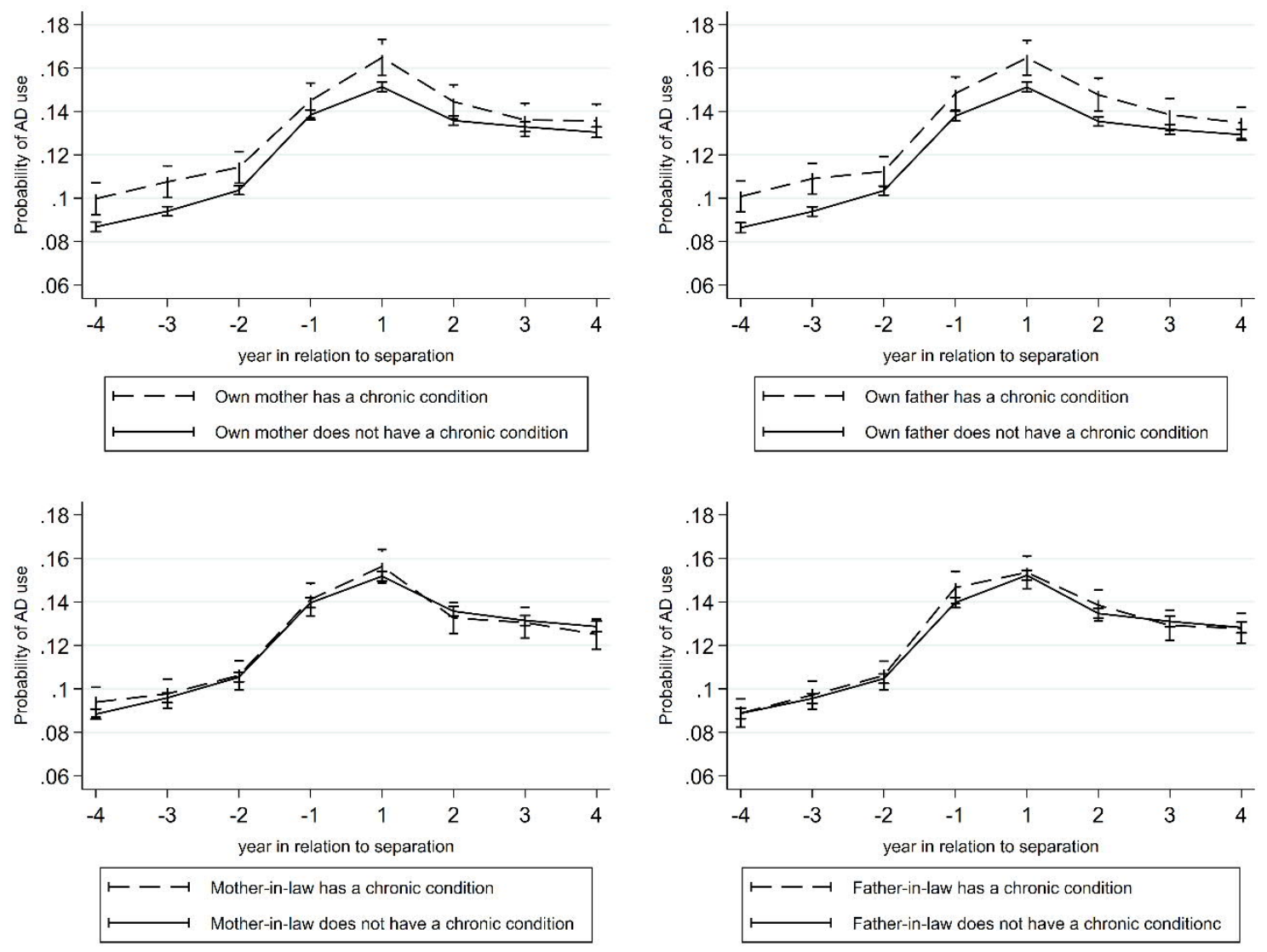

Adjusted for all mother's characteristics: age, calendar year, education, disposable income, employment status, municipality group, number of children, age of youngest child, living distance to youngest child's father, and repartnering 
SUPPORTING FIGURE 6. MOTHERS' ANTIDEPRESSANT USE BY DISTANCE TO GRANDPARENTS AT SEPARATION; ALL LIVING GRANDPARENTS IN THE SAME MODEL
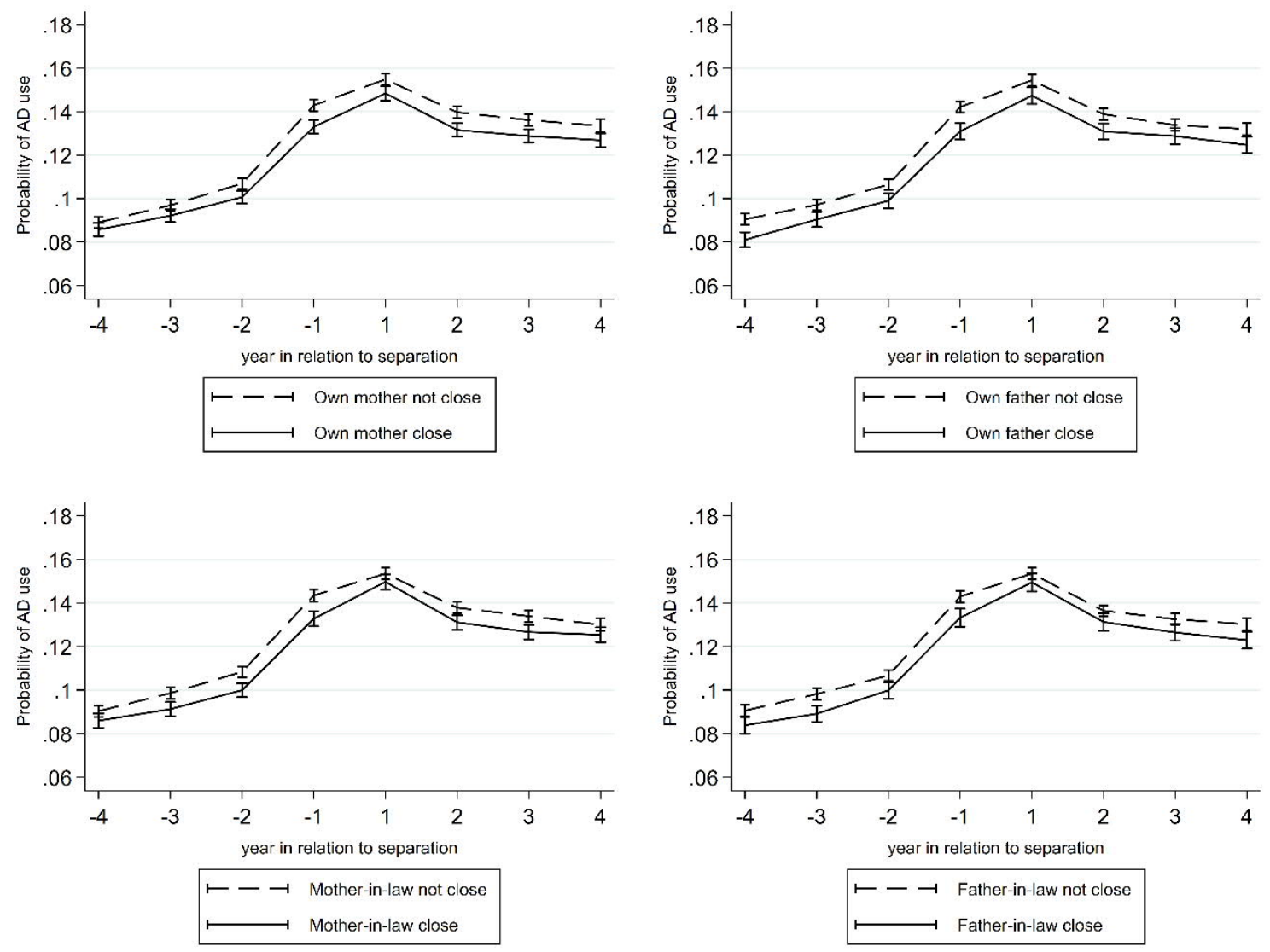

Adjusted for all mother's characteristics: age, calendar year, education, disposable income, employment status, municipality group, number of children, age of youngest child, living distance to youngest child's father, and repartnering 


\section{SUPPORTING FIGURE 7. MOTHERS’ ANTIDEPRESSANT USE BY THEIR OWN MOTHER'S}

\section{CHARACTERISTICS AT SEPARATION; ALL CHARACTERISTICS IN THE SAME MODEL}
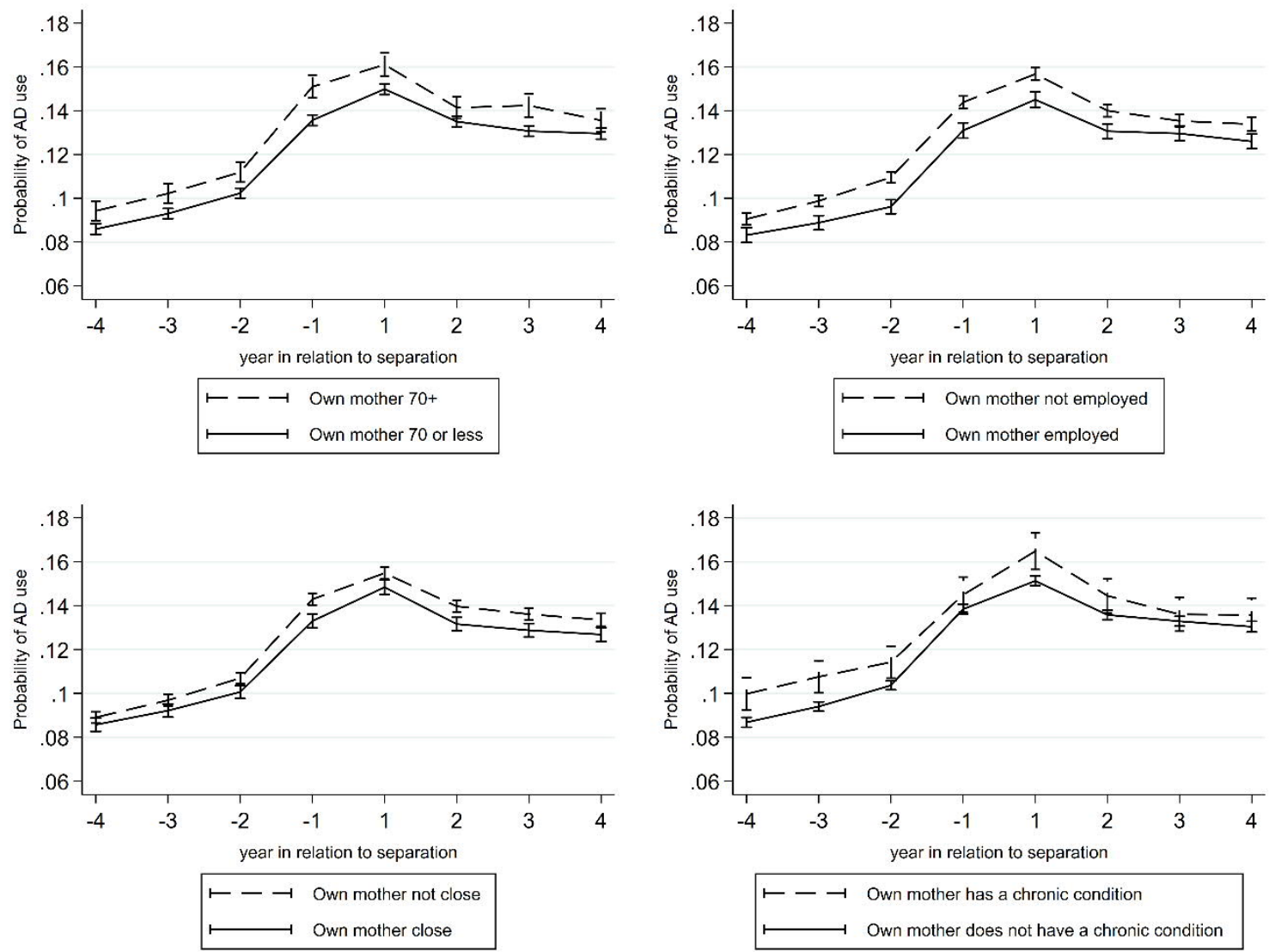

Adjusted for: All mother's characteristics: age, calendar year, education, disposable income, employment status, municipality group, number of children, age of youngest child, living distance to youngest child's father, and repartnering. All own mother's characteristics at separation: age, employment, distance to mother and health. 


\section{SUPPORTING FIGURE 8. MOTHERS’ ANTIDEPRESSANT USE BY THEIR OWN FATHER'S}

\section{CHARACTERISTICS AT SEPARATION; ALL CHARACTERISTICS IN THE SAME MODEL}
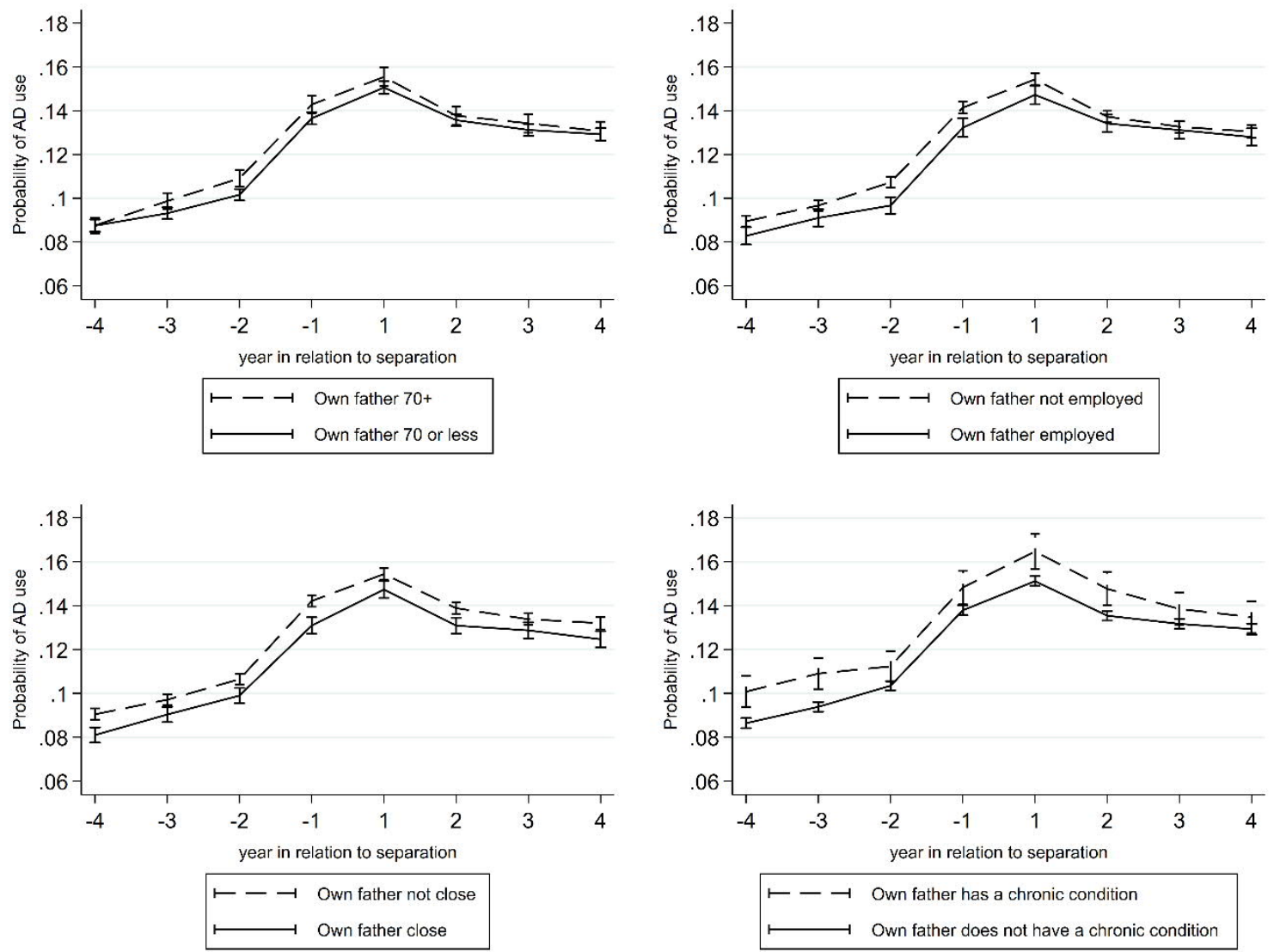

Adjusted for: All mother's characteristics: age, calendar year, education, disposable income, employment status, municipality group, number of children, age of youngest child, living distance to youngest child's father, and repartnering. All own father's characteristics at separation: age, employment, distance to mother and health. 


\section{SUPPORTING FIGURE 9. MOTHERS’ ANTIDEPRESSANT USE BY THEIR MOTHER-IN-LAW'S}

\section{CHARACTERISTICS AT SEPARATION; ALL CHARACTERISTICS IN THE SAME MODEL}
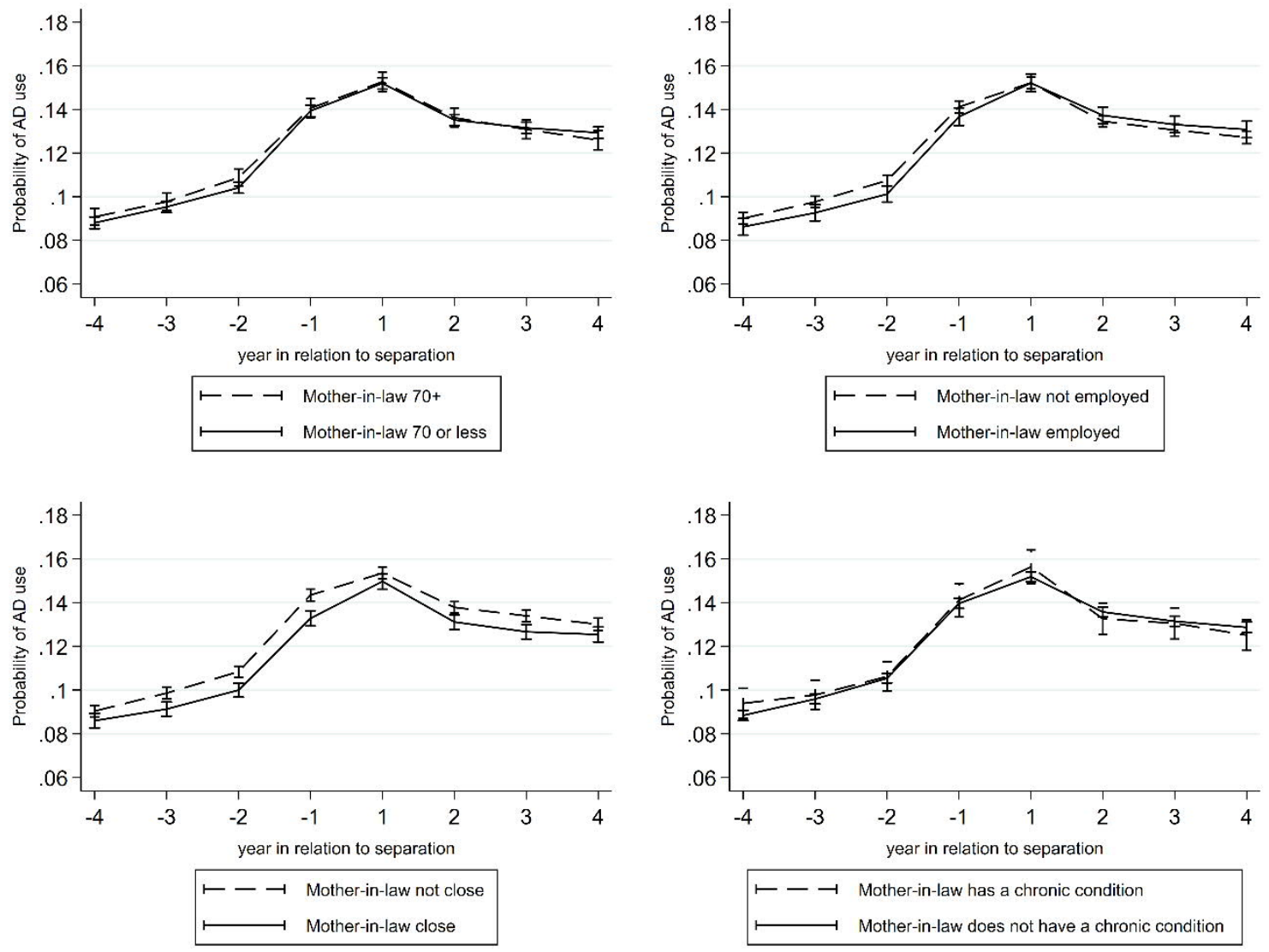

Adjusted for: All mother's characteristics: age, calendar year, education, disposable income, employment status, municipality group, number of children, age of youngest child, living distance to youngest child's father, and repartnering. All mother-in-law's characteristics at separation: age, employment, distance to mother and health. 


\section{SUPPORTING FIGURE 10. MOTHERS' ANTIDEPRESSANT USE BY THEIR FATHER-IN-LAW'S}

\section{CHARACTERISTICS AT SEPARATION; ALL CHARACTERISTICS IN THE SAME MODEL}
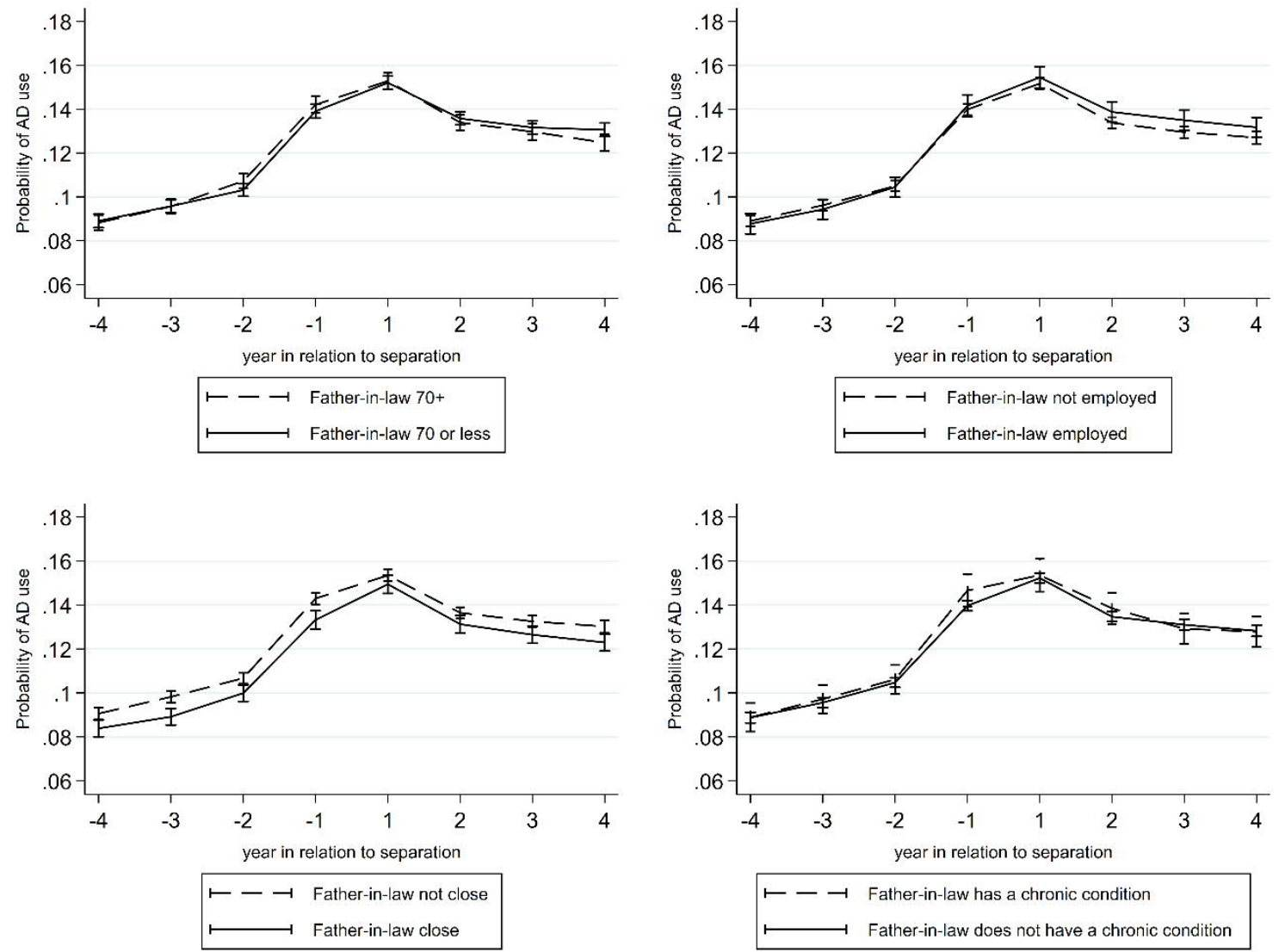

Adjusted for: All mother's characteristics: age, calendar year, education, disposable income, employment status, municipality group, number of children, age of youngest child, living distance to youngest child's father, and repartnering. All father-in-law's characteristics at separation: age, employment, distance to mother and health. 